ISSN: 0514-7336 — ISSN electrónico: 2386-3943

DOI: https://doi.org/10.14201/zephyrus202187105124

\title{
MEDITERRÁNEO Y ATLÁNTICO. ARQUEOMETALURGIA DEL BRONCE FINAL Y PRIMERA EDAD DEL HIERRO EN EL POBLADO DE EL MORREDÓN (FRÉSCANO, ZARAGOZA)
}

\section{Mediterranean and Atlantic. Archaeometallurgy of the Late Bronze Age and Early Iron Age from the Settlement El Morredón (Fréscano, Zaragoza)}

Paloma Aranda-Contamina*, Ignacio Montero-Ruiz**, José M. a Rodanés Vicente* y José Ignacio LORENZO LIZALDE***

* Dpto. de Ciencias de la Antigüedad. Facultad de Filosofía y Letras. Univ. de Zaragoza. Edificio Cervantes. Cl Corona de Aragón, 42. 5009Zaragoza.Correo-e: paranda@unizar.es; jrodanes@unizar.es. ID ORCID: https://orcid. org/0000-0002-9278-1355; https://orcid.org/0000-0001-9644-4252.

** Instituto de Historia-CSIC. Cl Albasanz, 26-28. Madrid 28037. Correo-e: ignacio.montero@cchs.csic.es. ID ORCID: https://orcid.org/0000-0003-0897-1031

*** Arqueólogo. Alfonso I el Batallador, 6-8.5430 María de Huerva (Zaragoza). Correo-e: jilorenzolizalde@gmail. com. ID ORCID: https://orcid.org/0000-0001-7580-6787.

Recepción: 31/07/2020; Revisión: 10/02/2021; Aceptación: 27/03/2021

Resumen: Las excavaciones realizadas entre 2002 y 2004 en El Morredón, yacimiento del Bronce Final y la Primera Edad del Hierro situado en el valle del Huecha, Zaragoza, han permitido la revisión del yacimiento y el estudio de sus materiales inéditos mediante nuevas técnicas y metodologías. El repertorio metálico del yacimiento se identifica con un conjunto de ámbito doméstico, mayoritariamente realizado en bronce, de reducida tipología, en el que predominan los objetos de adorno seguidos de armas y útiles de trabajo. Con el objetivo de conocer la composición de estos materiales se han realizado análisis mediante fluorescencia de rayos $\mathrm{X}-\mathrm{XRF}-$. Se ha documentado la presencia de dos aleaciones distintas: bronce binario de $\mathrm{Cu}-\mathrm{Sn}$ y ternario, $\mathrm{Cu}-$ $\mathrm{Sn}$ - $\mathrm{Pb}$. Esta composición apunta posibles conexiones con el Bajo Ebro y, a su vez, con la Meseta Sur, Levante o Andalucía, mientras la tipología de algunas piezas parece vinculada a la tradición del Bronce Atlántico o Centroeuropeo. La producción metalúrgica que se desarrolló en el propio poblado es una muestra más de la confluencia de tradiciones: mediterránea y atlántica, que cada vez se detecta con mayor claridad e intensidad en este territorio.

Palabras clave: valle del Ebro; Bronce Atlántico; Campos de Urnas; metalurgia; análisis de fluorescencia mediante rayos $\mathrm{X}$.

ABSTRACT: The excavations carried out between 2002 and 2004 at El Morredón, a Late Bronze and Early Iron Age site located in the Huecha valley, Zaragoza, have enabled the site to be revised and its unpublished materials to be studied using new techniques and methodologies. The metallic repertoire of the site is identified with a set of domestic objects, mostly made of bronze, of a reduced typology, in which decorative objects predominate, followed by weapons and working tools. In order to determine the composition of the metallic materials, X-ray 
fluorescence -XRF- analyses were carried out. The presence of two different alloys has been documented: $\mathrm{Cu}-\mathrm{Sn}$ binary bronze and $\mathrm{Cu}-\mathrm{Sn}-\mathrm{Pb}$ ternary bronze. This composition points to possible connections with the Lower Ebro and, in turn, with the Southern Meseta, Levante or Andalusia, while the typology of some pieces seems to be linked to the Atlantic or Central European Bronze tradition. The metallurgical production that took place in the settlement itself is another example of the confluence of Mediterranean and Atlantic traditions, which is becoming increasingly clearer and more intense in this area.

Key words: Ebro valley; Atlantic Bronze; Urnfield Culture; Metallurgy; X-Ray Fluorescence Analysis.

\section{Introducción}

El yacimiento de El Morredón (Fréscano, Zaragoza) ocupa gran parte de un cerro amesetado de grandes dimensiones a $3 \mathrm{~km}$ al oeste del río Huecha, rodeado de llanuras aluviales y en una posición estratégica de buena visibilidad de todo el valle bajo hasta su confluencia con el río Ebro. Es, junto al Alto de la Cruz de Cortes de Navarra (Maluquer et al., 1990), el poblado mejor conocido de una zona que destaca por la alta concentración de yacimientos del Bronce Final y Primera Edad del Hierro. Fue descubierto en 1970, aunque no fue excavado hasta comienzos del s. xxi cuando se llevaron a cabo las tres campañas desarrolladas entre 2002 y 2004. En estas intervenciones se documentó la existencia de un poblado en la cima y parte de la ladera sudoeste (Fig. 1). La estratigrafía permitió identificar sucesivas etapas que aportaron abundante material arqueológico (Aranda-Contamina et al., 2016, 2018), que se encuentra depositado en el Museo de Zaragoza.

La ocupación se extiende durante más de medio milenio, desde el s. XII cal AC hasta el s. vI cal AC, a lo largo de tres fases que han sido identificadas y caracterizadas a partir de la estratigrafía, plasmada en los informes de las campañas de excavación; del análisis de los materiales arqueológicos, y de la serie de dataciones radiocarbónicas (Fig. 2).

El inicio del poblamiento lo situamos en un momento del Bronce Tardío -Fase I-, en el s. XII cal AC, sin poder precisar el alcance o extensión del asentamiento. Probablemente estamos ante una primera ocupación del cerro con estructuras de hábitat realizadas con materiales perecederos y, por tanto, difíciles de identificar en el registro arqueológico. Esto no es exclusivo de El Morredón. Aunque escasos, se han identificado asentamientos similares en el Nivel i de Partelapeña de El Redal (Álvarez y Pérez Arrondo, 1987) o en los niveles más antiguos del Alto de la Cruz de Cortes -los denominados por los investigadores PVI, PV y PIV- (García López, 1994: 96; Armendáriz, 2008: 152). En el valle del Huecha, la mayor densidad de población durante la Edad del Bronce se concentra en la cercana Muela de Borja, cuya intensidad decae tras el Bronce Tardío de tipo Cogotas I para pasar a ocupar zonas de más baja altitud en el valle, donde ya encontramos yacimientos propios de Campos de Urnas (Aguilera, $1995)^{1}$. Esta hipótesis podría explicar esta primera ocupación relacionada con núcleos de la Meseta y anterior a la llegada de las influencias de los Campos de Urnas procedentes de las comarcas orientales del valle del Ebro.

Durante los ss. XI-X cal AC se desarrolló el poblado del Bronce Final -Fase II- limitado a la zona NE del cerro. Sería el primer hábitat estable, con una mayor extensión cronológica y estructural que la anterior. No obstante, el arrasamiento y aterrazamiento de estos niveles para la construcción de las siguientes fases, junto al alto grado de erosión del altozano, provocan una pobreza de restos constructivos que afortunadamente se compensa con la riqueza de la cultura material. La datación de esta Fase II adelanta la llegada de los primeros elementos de Campos de Urnas al valle del Huecha, respecto a gran parte de los esquemas cronológicos mantenidos hasta la fecha (Munilla et al., 1994/1996; Aguilera, 1995; Royo, 2005), en su mayor parte sustentados en cronologías relativas. Es ligeramente más tardía que la Fase I del Cabezo de la Cruz de La

1 Aguilera, I.: La comunidad prehistórica de La Muela de Borja. 2550-1200 CAL ANE. Tesis doctoral inédita defendida en 2017 en la Univ. de Zaragoza. 

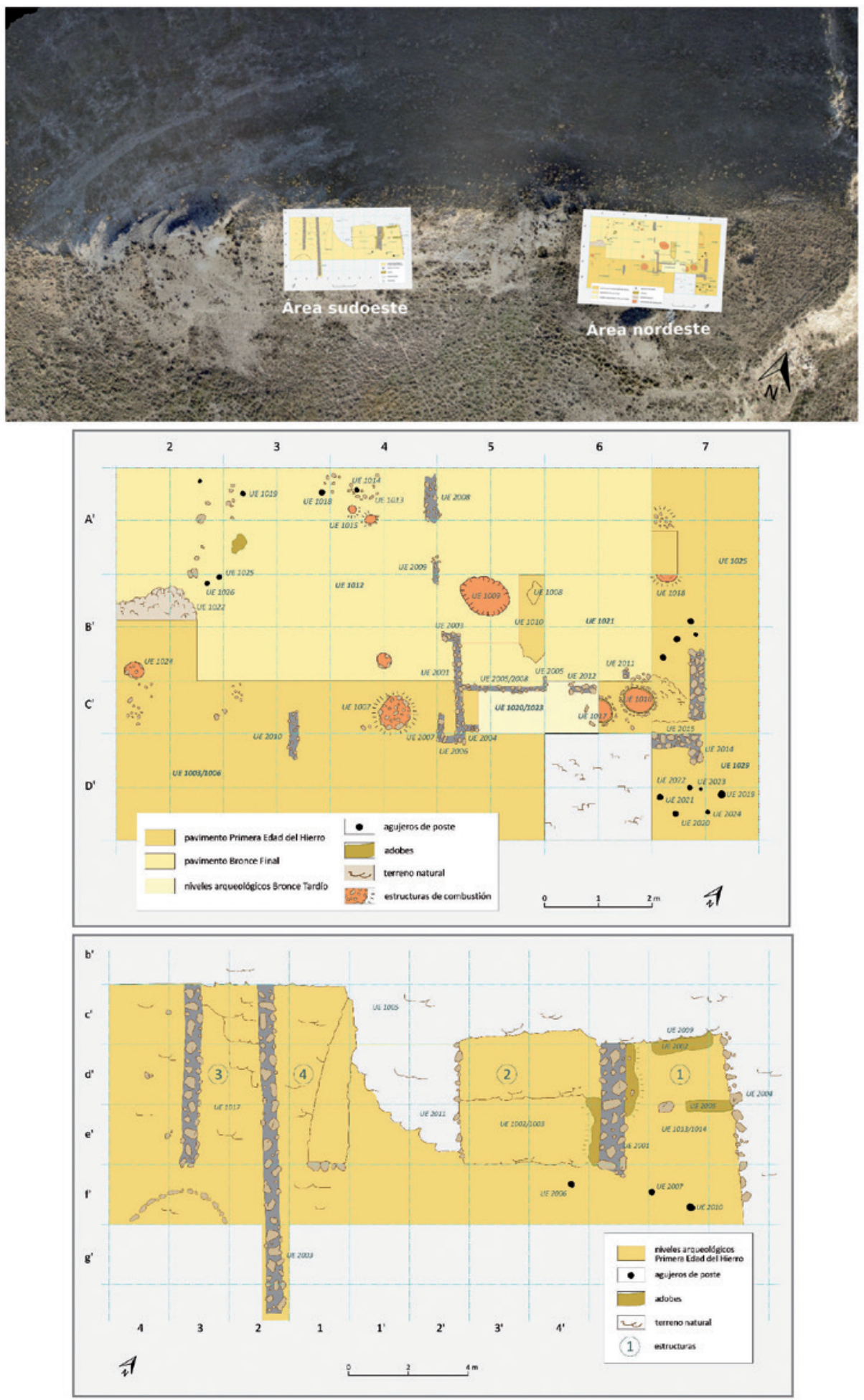

FIG. 1. Excavaciones en El Morredón: planimetría de las dos zonas excavadas en las zonas NE y SO y su localización en el cabezo del yacimiento. 
108 P. Aranda-Contamina, I. Montero-Ruiz, J. M. ${ }^{a}$ Rodanés Vicente y J. I. Lorenzo Lizalde / Mediterráneo y Atlántico...

\begin{tabular}{|c|c|c|c|c|c|}
\hline Sigla & Contexto & Fecha BP & $68 \%$ & $95 \%$ & cal med BC \\
\hline D-AMS 021821 & UE 1023 Fase I & $2946 \pm 29$ & $1212-1117$ & $1257-1051$ & 1156 \\
\hline D-AMS 021820 & $\begin{array}{c}\text { UE 1012 Fase } \\
\text { II }\end{array}$ & $2826 \pm 37$ & $1020-922$ & $1110-900$ & 980 \\
\hline D-AMS 021822 & $\begin{array}{c}\text { UE 1006 Fase } \\
\text { II }\end{array}$ & $2799 \pm 33$ & $996-914$ & $1042-846$ & 952 \\
\hline D-AMS 021824 & $\begin{array}{c}\text { UE 1010 Fase } \\
\text { III }\end{array}$ & $2484 \pm 22$ & $756-544$ & $770-524$ & 636 \\
\hline
\end{tabular}

Fig. 2. Dataciones radiocarbónicas de El Morredón calibradas con el programa OxCal v.4.3.2 (Reimer et al., 2013) con la curva de calibración IntCal13.

Muela (Picazo y Rodanés, 2009: 247), y encuentra paralelos en poblados como Genó, en el Segre-Cinca (Maya et al., 1998), o en el Bajo Aragón con los frecuentemente citados de Palermo II, Cabezo de Monleón y Záforas (Álvarez, 1992-1993). Se correspondería con el Bronce Final inb o Campos de Urnas Recientes.

Ya en la Primera Edad del Hierro -Fase III-, entre los ss. VIII y VI cal AC, se extiende por el cabezo mediante el aterrazamiento de su ladera donde se localizan distintas estructuras domésticas (Aranda-Contamina et al., 2016). Es el momento de esplendor de numerosos poblados en el valle del Huecha, como los de Fréscano: La Cruz, San Gil, Burrén y Burrena, El Quez de Alberite y La Corona-Esquilar de Borja (Aguilera y Royo, 1978) o el Alto de la Cruz de Cortes (Maluquer et al., 1990), pero también en todo el valle medio del Ebro, como el Cabezo de la Cruz de La Muela (Picazo y Rodanés, 2009), Las Eretas de Berbinzana en Navarra (Armendáriz, 1995-96), La Hoya en Álava o Partelapeña en La Rioja (Álvarez y Clavijo, 1987). Esta fase se enmarcaría en los esquemas tradicionales dentro de los Campos de Urnas del Hierro. Se documenta un incendio generalizado que supondría el final de la ocupación, como sucede en otros yacimientos cercanos: prib del Alto de la Cruz de Cortes (Maluquer et al., 1990), la Corona-Esquilar, el Quez o El Convento de Mallén (Aguilera y Royo, 1978).

Sus pobladores, a lo largo de los siglos, fabricaron sus propios objetos en cerámica, piedra o metal, al mismo tiempo que se producirían intercambios y relaciones, más difusas o menos intensas, con territorios alejados, pero muy estrechas con los poblados del entorno, como se aprecia en las múltiples similitudes que observamos en diferentes aspectos de la cultura material (Rodanés y Picazo, 2017). Estos elementos, sin duda, nos permiten determinar la diversidad y la complejidad características de estas sociedades en su más amplio sentido, pero en especial reportan gran cantidad de información sobre su sistema productivo y tecnológico. En este caso concreto, una vez realizado el estudio tipológico en un trabajo anterior (Aranda-Contamina et al., 2020), nos centraremos en la producción de los materiales metálicos.

\section{Los objetos metálicos: tipología}

Se han inventariado 52 piezas de diferentes formas y funciones (Fig. 3). El número de restos es reducido teniendo en cuenta la extensión del lugar. Se trata de un conjunto de ámbito doméstico, de tipología reducida (Fig. 4), con pocas armas (Fig. 5) y un predominio de objetos de adorno. Son escasos los elementos singulares con valor cronológico, pero destacan algunos restos que documentan una actividad metalúrgica de producción. Mayoritariamente están realizadas en bronce, con escasos útiles en hierro. Es el repertorio habitual en poblados de estas cronologías, con evidentes paralelos en asentamientos como el Alto de la Cruz de Cortes de Navarra (Maluquer et al., 1990) o el Cabezo de la Cruz de La Muela en Zaragoza (Picazo y Rodanés, 2009).

Entre los elementos singulares destacaremos un hacha de talón con dos anillas (Fig. 5) procedente de la Fase II, que tipológicamente se integra en el Bronce Final Atlántico, tipo distribuido mayoritariamente por el No (Monteagudo, 1977: 157-158), aunque también hay ejemplares cercanos como las otras dos hachas de talón procedentes de El 


\begin{tabular}{|c|c|c|c|c|c|c|c|c|c|}
\hline $\begin{array}{c}\text { N. }{ }^{\circ} \\
\text { INVENTARIO }\end{array}$ & EsTRATIGRAFÍA & FASE & DESCRIPCIÓN & Metal & $\begin{array}{l}\text { LONGITUD } \\
(\mathrm{mm})\end{array}$ & $\begin{array}{l}\text { ANCHURA } \\
(\mathrm{mm})\end{array}$ & $\begin{array}{c}\text { Grosor } \\
(\mathrm{mm})\end{array}$ & $\begin{array}{c}\text { Peso } \\
(\mathrm{gr})\end{array}$ & XRF \\
\hline 6379 & 1022, в 7 & II & anilla sección elíptica & Ae & 20 & 3,5 & 2 & 1,64 & $\mathrm{x}$ \\
\hline 15012 & 1021, в6 & II & barrita-lingote incompleta & Ae & 85 & 6 & 4 & 13 & $\mathrm{x}$ \\
\hline 15013 & 1021, в 6 & II & fragmento lámina forma circular & $\mathrm{Ae}$ & $54-59$ & $31-37$ & $0,5-1$ & 13,5 & $\mathrm{x}$ \\
\hline 54272 & 1021 & II & hacha de talón y dos anillas & Ae & 206 & 70 & 30 & 959 & - \\
\hline $11365 \mathrm{~A}$ & 1006, A5 & II & lámina rectangular sección plana & $\mathrm{Ae}$ & 35 & $17-19$ & 3 & 5,91 & $\mathrm{x}$ \\
\hline 11365 B & 1006, A 5 & II & objeto tubular & $\mathrm{Ae}$ & 18 & 11 & 8 & 1,07 & $\mathrm{x}$ \\
\hline 2411 & 1000, в 7 & III & varilla sección rectangular & Ae & 80 & 3 & 2 & 3,39 & $\mathrm{x}$ \\
\hline 2412 & 1000, в 7 & III & anilla sección circular & $\mathrm{Ae}$ & 14 & 2 & 1,5 & 0,64 & $\mathrm{x}$ \\
\hline 2470 & $1000, \mathrm{C} 7$ & III & botón cónico & $\mathrm{Ae}$ & 15 & 5 & 1 & 2,18 & $\mathrm{x}$ \\
\hline 3131 & 1001, в 4 & III & fragmento lingote plano-convexo & Ae & 47 & 43 & 14 & 83 & $\mathrm{x}$ \\
\hline 3399 & $\begin{array}{l}\text { 1004, в9-в 10 } \\
\text { (Estructura 2) } \\
\end{array}$ & III & pasador sección plana & $\mathrm{Ae}$ & 23 & 10 & 1 & 2,14 & $\mathrm{x}$ \\
\hline 3400 & $\begin{array}{l}\text { 1004, в9-в } 10 \\
\text { (Estructura 2) }\end{array}$ & III & arandela abierta sección cuadrada & Ae & 17 & $2,5-3$ & 1,5 & 1,12 & $\mathrm{x}$ \\
\hline 3688 & $\begin{array}{l}\text { 1007, B8/Sector } \\
\text { XI (Estructura 1) } \\
\end{array}$ & III & objeto tubular & $\mathrm{Ae}$ & 33 & 4 & 2 & 0,66 & $\mathrm{x}$ \\
\hline 16257 & 1006, D3 & III & barrita-lingote & $\mathrm{Ae}$ & 152 & 6 & 4 & 17,2 & $\mathrm{x}$ \\
\hline 18851 & 1001, a4 & III & objeto tubular & $\mathrm{Ae}$ & 30 & 3 & 1 & 0,55 & $\mathrm{x}$ \\
\hline 19050 & 1008, e2 & III & fragmento informe & Ae & 7 & 4 & 2 & 0,16 & - \\
\hline 19077 & $1014, \mathrm{f} 2$ & III & punta de flecha pedúnculo y aletas & $\mathrm{Ae}$ & $18-22$ & $2-18$ & 1 & 0,98 & $\mathrm{x}$ \\
\hline 19078 & $1013, \mathrm{f} 2$ & III & $\begin{array}{l}\text { fragmento lámina rectangular } \\
\text { sección plana }\end{array}$ & $\mathrm{Ae}$ & $17-20$ & 13 & 1 & 0,67 & $\mathrm{x}$ \\
\hline 19167 & 1000, в 7 & III & botón semiesférico & $\mathrm{Ae}$ & 8 & 3,5 & 1 & 0,46 & $\mathrm{x}$ \\
\hline 19168 & 1001, в 7 & III & botón semiesférico & $\mathrm{Ae}$ & 7 & 3 & 1 & 0,35 & $\mathrm{x}$ \\
\hline 19169 & 1025, в 7 & III & fragmentos lascas muy pequeńas & Ae & - & - & - & 1,6 & - \\
\hline 19170 & 1025, в 7 & III & fragmento lámina & Ae & 28 & 11 & 2 & 2,79 & - \\
\hline 19973 & 1002, C7 & III & fragmento vástago & $\mathrm{Ae}$ & 12 & 2,5 & - & 0,23 & - \\
\hline 20039 & 1003, c7 & III & objeto tubular & Ae & 30 & 4 & 1 & 0,97 & $\mathrm{x}$ \\
\hline 20490 & $1025, \mathrm{C} 7$ & III & fragmento enganche & $\mathrm{Ae}$ & $5-6$ & $2-4$ & 2 & 0,15 & - \\
\hline 21020 & $1000, \mathrm{D} 7$ & III & resto metalúrgico & $\mathrm{Ae}$ & 8 & 9 & 5 & 0,41 & $\mathrm{x}$ \\
\hline 21941 & $\begin{array}{l}1002 \\
\text { (Estructura 5) }\end{array}$ & III & goterón de fundición & $\mathrm{Ae}$ & 17 & 12 & 8 & 3,9 & $\mathrm{x}$ \\
\hline 21942 & \begin{tabular}{|l|}
1002 \\
(Estructura 5)
\end{tabular} & III & goterón de fundición & $\mathrm{Ae}$ & 14 & 12 & 5 & 4,25 & $\mathrm{x}$ \\
\hline 22056 & 1001, Cata A & III & fragmento informe & $\mathrm{Ae}$ & 15 & 11 & 4,5 & 1,47 & - \\
\hline 22225 & 1002, Cata A & III & fragmento lingote & $\mathrm{Ae}$ & 20 & 11 & 7 & 9,44 & $\mathrm{x}$ \\
\hline $22749 \mathrm{~A}$ & 1001, Cata D & III & escoria & $\mathrm{Ae}$ & 8 & 7 & 5 & 0,44 & $\mathrm{x}$ \\
\hline 22749 & 1001, Cata D & III & fragmento muelle & $\mathrm{Ae}$ & 6,5 & 3 & 1 & 0,12 & $\mathrm{x}$ \\
\hline 19033.01 & superficial, d2 & - & $\begin{array}{l}\text { fragmento placa muy fino } \\
\text { (anillo, botón...) }\end{array}$ & Ae & 14 & 10 & 1 & 0,31 & - \\
\hline 23184 & \begin{tabular}{|l|} 
superficie \\
zona central \\
\end{tabular} & - & punta de flecha ojival & $\mathrm{Ae}$ & $22-23$ & $13-15$ & 1 & 1,06 & $\mathrm{x}$ \\
\hline 23284 & superficial & - & anilla incompleta sección circular & $\mathrm{Ae}$ & 21 & $1,5-2,4$ & $1,5-2$ & 0,94 & $\mathrm{x}$ \\
\hline
\end{tabular}




\begin{tabular}{|c|c|c|c|c|c|c|c|c|c|}
\hline $\begin{array}{c}\text { N. }{ }^{\circ} \\
\text { INVENTARIO }\end{array}$ & ESTRATIGRAFÍA & FASE & DESCRIPCIÓN & Metal & $\begin{array}{l}\text { LONGITUD } \\
(\mathrm{mm})\end{array}$ & $\begin{array}{l}\text { ANCHURA } \\
(\mathrm{mm})\end{array}$ & $\begin{array}{c}\text { Grosor } \\
(\mathrm{mm})\end{array}$ & $\begin{array}{c}\text { Peso } \\
(\mathrm{gr})\end{array}$ & XRF \\
\hline 23285 & superficial & - & punta flecha pedúnculo y aletas & $\mathrm{Ae}$ & 22 & $8-16$ & 1 & 2,5 & $\mathrm{x}$ \\
\hline 23286 & superficial & - & fragmento lámina & Ae & 10 & 11 & 2 & 1,21 & $\mathrm{x}$ \\
\hline 23399 & $\begin{array}{l}\text { superficie zona } \\
\text { este }\end{array}$ & - & fragmento pulsera sección elíptica & $\mathrm{Ae}$ & 18 & 6,5 & 2 & 1,16 & $\mathrm{x}$ \\
\hline 23400 & superficial & - & $\begin{array}{l}\text { fragmento anillo decorado con } \\
\text { motivos punteados romboidales }\end{array}$ & Ae & 21 & 9 & 1 & 1,39 & $\mathrm{x}$ \\
\hline 23401 & $\begin{array}{l}\text { superficie } \\
\text { zona central }\end{array}$ & - & $\begin{array}{l}\text { punta de flecha nervio central } \\
\text { y aletas }\end{array}$ & $\mathrm{Ae}$ & 14 & $11-14$ & $2-3$ & 1,76 & $\mathrm{x}$ \\
\hline 25001 & $\begin{array}{l}\text { superficie- } \\
\text { próximo terrera }\end{array}$ & - & fragmento lámina sección plana & Ae & 30 & 20 & 2 & 4,50 & - \\
\hline $3400 \mathrm{~A}$ & $\begin{array}{l}\text { 1004, в9-в } 10 \\
\text { (Estructura 2) }\end{array}$ & III & hoz & $\mathrm{Fe}$ & 220 & 18 & 3 & 25,6 & - \\
\hline 3668 & $\begin{array}{l}\text { 1004, в10-с10 } \\
\text { (Estructura 2) }\end{array}$ & III & fragmentos informes & $\mathrm{Fe}$ & 15 & 15 & 10 & 3,35 & - \\
\hline 21943 & $\begin{array}{l}1002 \\
\text { (Estructura 5) }\end{array}$ & III & fragmento útil cuadrangular & $\mathrm{Fe}$ & 40 & 35 & 19 & 36,8 & - \\
\hline 21021 & $1000, \mathrm{D} 7$ & III & $\begin{array}{l}\text { fragmento vástago sección } \\
\text { aplanada }\end{array}$ & $\mathrm{Fe}$ & 43 & $9-10$ & 9 & 4,48 & - \\
\hline $\begin{array}{l}21840- \\
21841\end{array}$ & $\begin{array}{l}1000 \\
\text { (Estructura 5) }\end{array}$ & III & fragmentos informes & $\mathrm{Fe}$ & $13-14$ & $11-14$ & 8 & 2,67 & - \\
\hline 23185 & 1000-superficial & III & fragmento vástago sección circular & $\mathrm{Fe}$ & 29 & $3,5-4$ & - & 1 & - \\
\hline 23287 & superficial & - & fragmento informe & $\mathrm{Fe}$ & 20 & 15 & 4 & 1,89 & - \\
\hline 23288 & superficial & - & escoria & $\mathrm{Fe}$ & 18 & 15 & 7 & 2,55 & - \\
\hline 23402 & $\begin{array}{l}\text { superficial hacia } \\
\text { viviendas }\end{array}$ & - & fragmento útil (hacha, cincel...) & $\mathrm{Fe}$ & 65 & 39 & 20 & 134 & - \\
\hline
\end{tabular}

Fig. 3. Inventario de los materiales metálicos de las excavaciones de El Morredón, según numeración de inventario de la excavación.

\begin{tabular}{|l|c|}
\hline \multicolumn{1}{|c|}{ Tipología } & $\begin{array}{c}\text { N. } \\
\text { DE RESTOS }\end{array}$ \\
\hline 1. Hacha de talón & 1 \\
\hline 2. Puntas de flecha & 4 \\
\hline 3. Objetos de adorno & \\
\hline 3.1. Botones & 3 \\
\hline 3.2. Objetos anulares & 4 \\
\hline 3.3. Anillos & 3 \\
\hline 3.4. Pasador & 1 \\
\hline 3.5. Pulsera & 1 \\
\hline 3.6. Enganche & 1 \\
\hline 3.7. Muelle & 1 \\
\hline 3.8. Cuentas tubulares & 4 \\
\hline 3.9. Láminas o placas & 6 \\
\hline 4. Útiles en hierro & 6 \\
\hline 5. Restos del trabajo metalúrgico & \\
\hline 5.1. Barritas-lingote y lingote plano-convexo & 6 \\
\hline 5.2. Escorias & 6 \\
\hline 5.3. Molde & 1 \\
\hline
\end{tabular}

Fig. 4. Clasificación tipológica del conjunto de materiales metálicos de El Morredón.
Morredón (García-Arilla, 2015: 26) o de las proximidades de Pamplona (Castiella y Sesma, 19881989: 397). Los objetos de adorno son numerosos (Fig. 6). Sirvan de muestra tres botones semiesféricos y cónicos, objetos anulares como anillas y arandelas, varios anillos entre los que se encuentra uno con un singular diseño de punteado lineal formando motivos romboidales, cuentas tubulares, láminas enrolladas o placas metálicas, entre otros. A ello se suman útiles y herramientas en hierro, entre los que destaca una hoz completa, si bien, a tenor de los escasos restos, este metal es todavía poco frecuente (Fig. 7).

La gran mayoría de los metales pertenecen a la Fase III, correspondiente a la Primera Edad del Hierro, con escasas piezas de la Fase II del Bronce Final y ninguna de la Fase I perteneciente al Bronce Tardío. No podemos extraer de ello conclusiones cronoculturales determinantes ya que esta distribución podría estar relacionada con la extensión de la excavación y 
su afección en cada una de las fases.

Además de piezas acabadas, existen materiales localizados que señalan la existencia de trabajo metalúrgico en el propio yacimiento, como barritas-lingote, un lingote plano-convexo, escorias y otros restos de fundición (Fig. 8), así como un molde bivalvo de broche de cinturón y cuatro varillas en piedra arenisca (Fig. 9) (Aranda-Contamina et al., 2020). Si bien es cierto que no se han documentado estructuras específicas, es más que evidente que se llevó a cabo una producción metalúrgica en dos aleaciones distintas: bronces binarios de $\mathrm{Cu}-\mathrm{Sn}$ y ternarios de $\mathrm{Cu}-\mathrm{Sn}$ $\mathrm{Pb}$, tal como nos indican los análisis que comentaremos a continuación y que configuran la base de este trabajo.

\section{Análisis mediante \\ fluorescencia de rayos $\mathrm{X}$}

Se han analizado 35 piezas de base cobre, lo que supone un alto porcentaje del total que afecta a todas las tipologías del conjunto. El estado de conservación de los objetos ha condicionado en parte el muestreo disponible, habiéndose elegido aquellas piezas que permitían una mejor manipulación para eliminar la pátina superficial. En determinados casos el material se encontraba completamente mineralizado o era muy frágil para realizar una
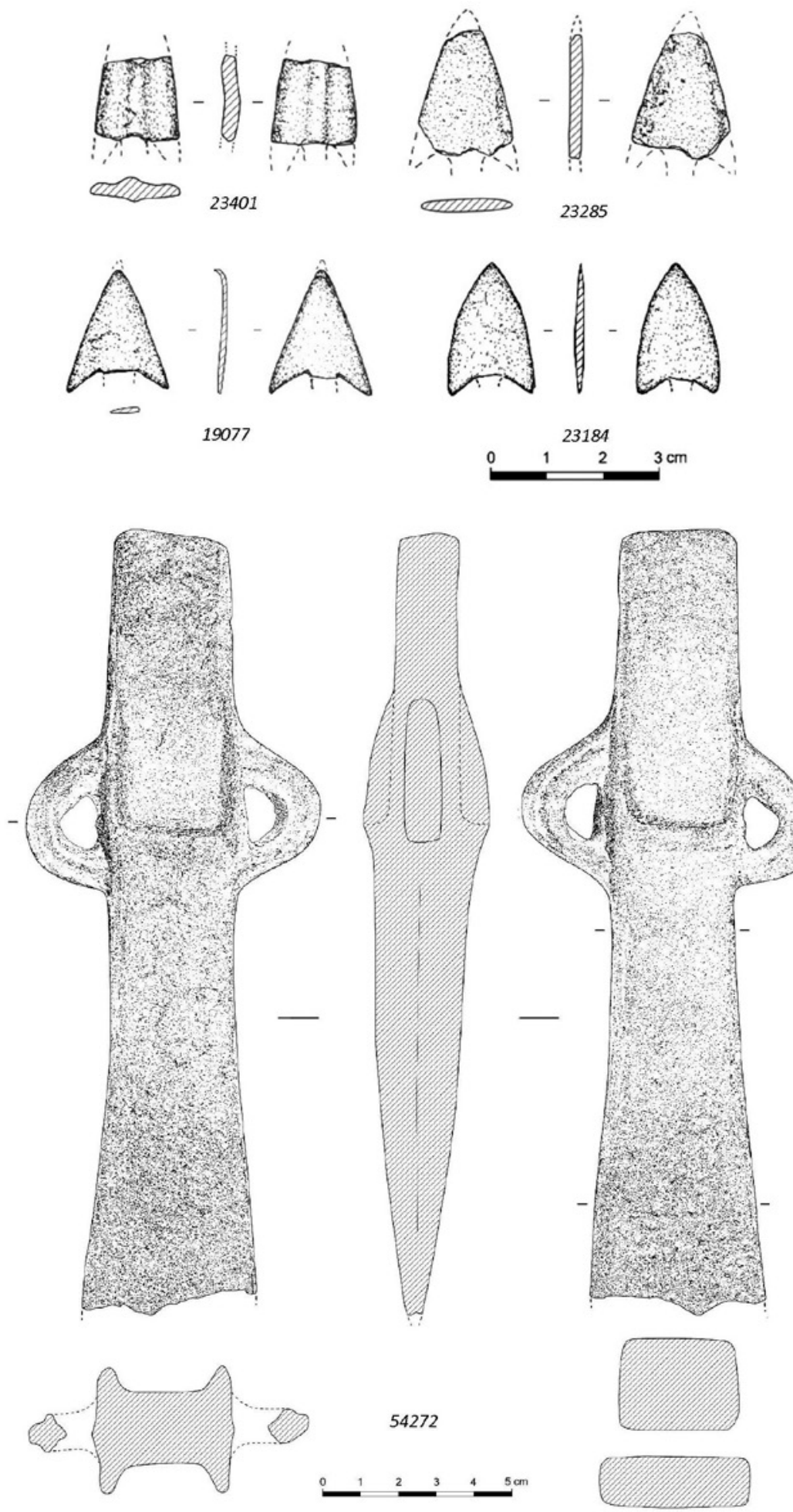

Fig. 5. Puntas de flecha y hacha de talón de El Morredón. 
2)

19167

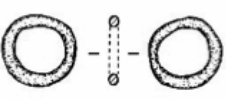

2412

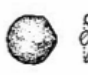

19168
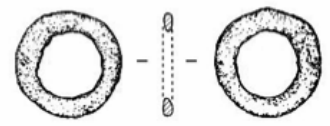

6379

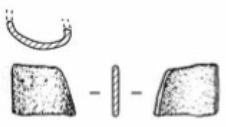

23398
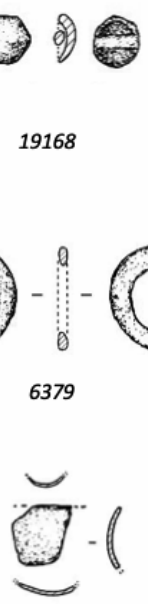

19033.1

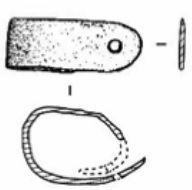

22749

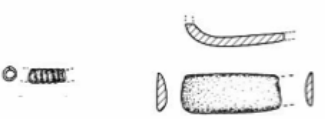

23399
3399

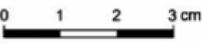

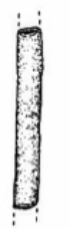

20039
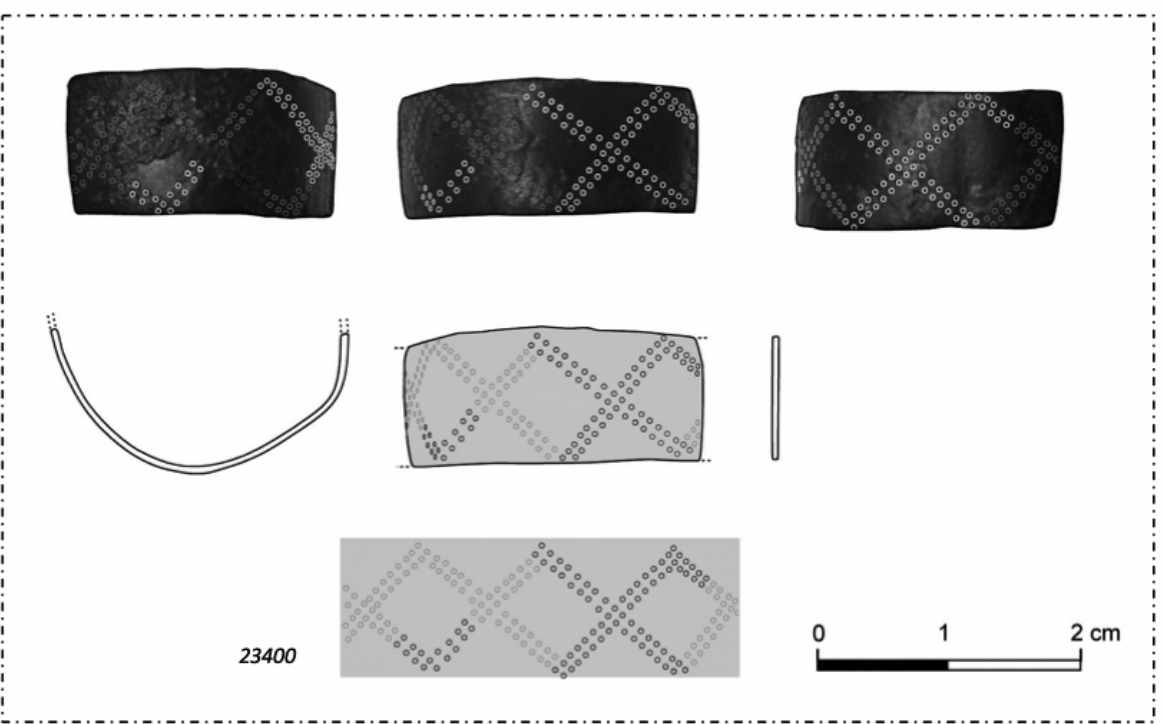

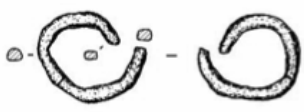

3400
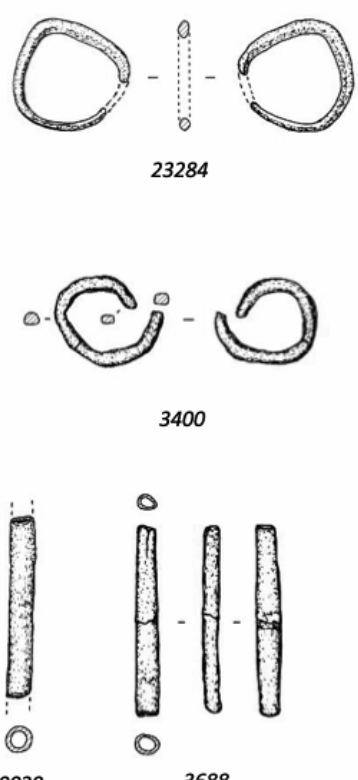

23284

3688
Fig. 6. Objetos de adorno, entre los que destaca el fragmento de anillo con motivos punteados rectilíneos y diseño romboidal de El Morredón. limpieza, indicándose con una $\mathrm{P}$-de pátina- al final del número de análisis cuando no se analizó metal sano. En el estudio vamos a separar las piezas manufacturadas de los restos vinculados con la producción de metal. Los resultados se presentan agrupados en la Fig. 10 expresados como porcentaje en peso.

Los análisis se realizaron en el Museo de Zaragoza utilizando el espectrómetro portátil InNOv-X del Museo Arqueológico Nacional y cuyas características generales se encuentran descritas en Rovira y Montero (2018). Este espectrómetro tiene el inconveniente de un límite de detección elevado para plata y antimonio $-0,15 \%$ - que condiciona las comparaciones con datos de otros análisis anteriores realizados dentro del Proyecto "Arqueometalurgia de la Península Ibérica" o de otros investigadores que emplean otras técnicas de análisis elemental.

\subsection{Objetos de metal}

Disponemos de 27 piezas analizadas, de las cuales cinco pertenecen a 
la Fase II, trece a la Fase III y otras nueve fueron recuperadas en niveles superficiales, pero que tipológicamente encajan en la más reciente. Desde una perspectiva general todas las aleaciones son bronces, con un rango entre el 2 y el $14 \%$ Sn. Solo dos objetos se salen de esta norma. Por un lado, un botón con travesaño -PA25427- que apenas contiene el $1,4 \% \mathrm{Sn}$, pero cuyo análisis parece conservar todavía restos de la pátina y corrosión -elevado contenido en $\mathrm{Fe}-$. Los análisis de algunas piezas indican que se detecta algo más de estaño y plomo cuando la limpieza del metal es más completa y se eliminan pequeños restos de corrosión (Fig. 10). En este sentido es bastante probable que el botón se acerque al $2 \%$ en su contenido original de estaño y deba clasificarse como bronce pobre $->6 \% \mathrm{Sn}$-.

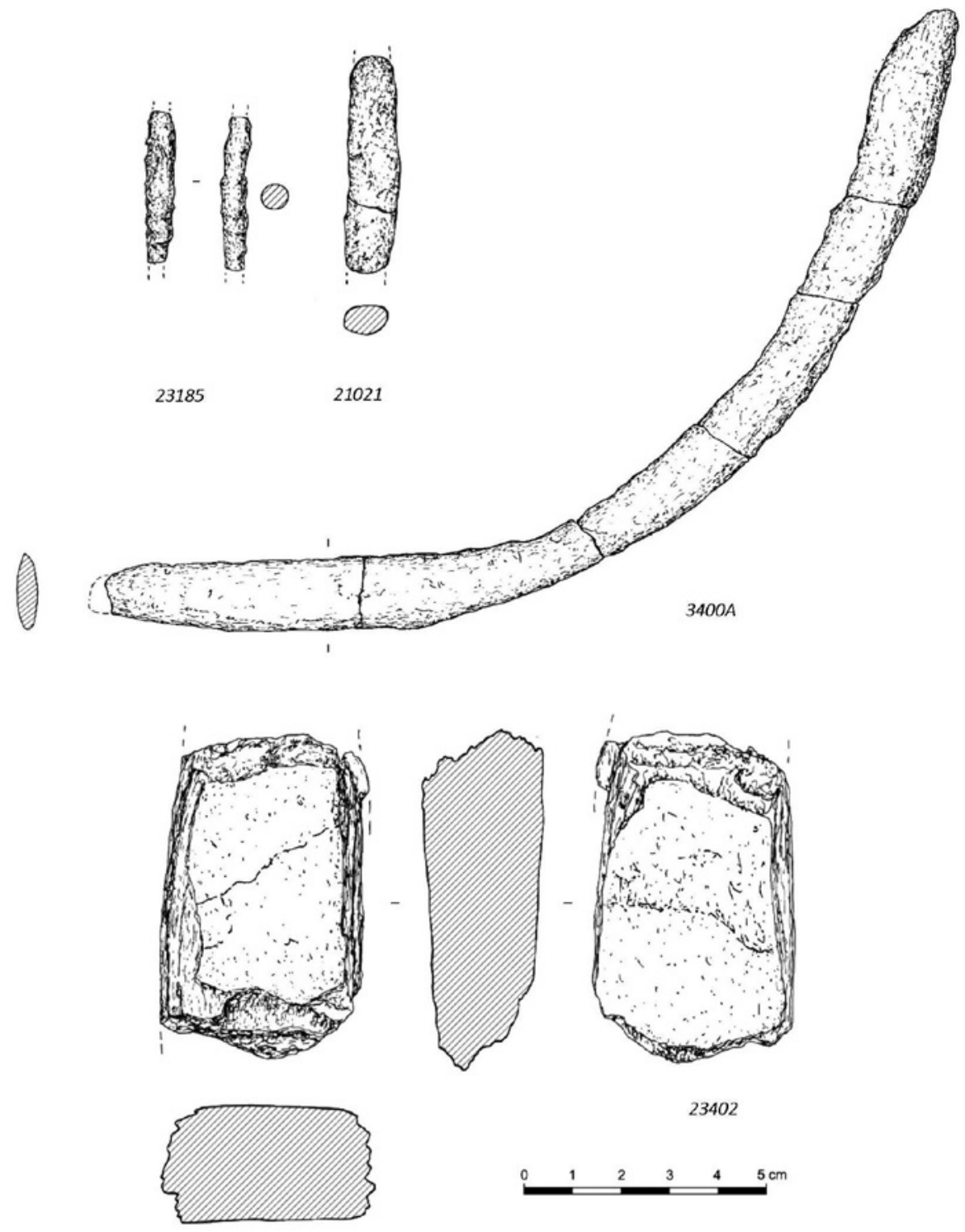

FIG. 7. Material metálico realizado en hierro. La otra pieza que se separa por su contenido elevado de estaño es una cuenta globular -PA25414-, pero que se encuentra muy corroída ya que el análisis incluye un $47 \%$ de elementos ligeros - LE- cuantificados por lo que la composición no la podemos considerar representativa de la proporción aleada de estaño.

La media de estaño de todo el conjunto es baja $-8,1 \%$ Sn-con solo una pequeña diferencia entre las dos fases bajo estudio ya que el material de la Fase II tiene una media del 7,0 \% si eliminamos la cuenta globular en el cálculo.

El plomo es, junto con el estańo, el elemento que encontramos en todas las muestras, aunque aquí la variación en las proporciones es mayor. Once piezas presentan contenido por debajo del $2 \% \mathrm{~Pb}$ y las clasificamos como bronces binarios ${ }^{2}$. Otras 16 son

2 Se establece el límite del $2 \% \mathrm{~Pb}$ para considerar una aleación plomada, siguiendo lo establecido por el proyecto de referencia "Arqueometalurgia de la Península 
bronces plomados, y la mitad de ellas podemos clasificarlas como muy plomadas por llevar más del $10 \%$ $\mathrm{Pb}$. Las piezas plomadas y muy plomadas son mayoritarias en la Edad del Hierro, y solo en el Bronce Final detectamos la excepción de una arandela -PA25408; n. ${ }^{\circ}$ inv. 6379- que lleva el $11 \% \mathrm{~Pb}$. No obstante, cabe mencionar que es habitual durante el Bronce Final avanzado en el cuadrante noroccidental de la Península Ibérica la aparición de algunos bronces plomados con altos niveles de $\mathrm{Pb}$ (Rovira y Renzi, 2010: 110).

Los rangos en el contenido de plomo se encuentran en sintonía con lo conocido en estos periodos, con poca presencia en el Bronce Final y una media del 8,1\% para la Primera Edad del Hierro, ya que la proporción

Ibérica”. Las razones son, como sus investigadores señalan, la dificultad en precisar el contenido en plomo en los metales de base cobre, dada la formación de segregados, $y$, en consecuencia, la aleatoriedad de su distribución en un área determinada, sobrevalorando su presencia. No obstante, en El Morredón algunas de ellas presentan valores ligeramente inferiores pero muy cercanos al $2 \%$, como una punta de flecha con $1,9 \% \mathrm{~Pb}$ y una espiral con 1,68 $\%$ de $\mathrm{Pb}$. El resto de los bronces que se han considerado binarios -10 casos- presentan plomo, pero en concentraciones menores del $1 \%$, por lo que lo consideramos impurezas del metal.

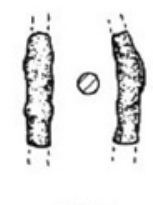

19973 de plomo aumenta en este último periodo (Rovira, 1993: 48).
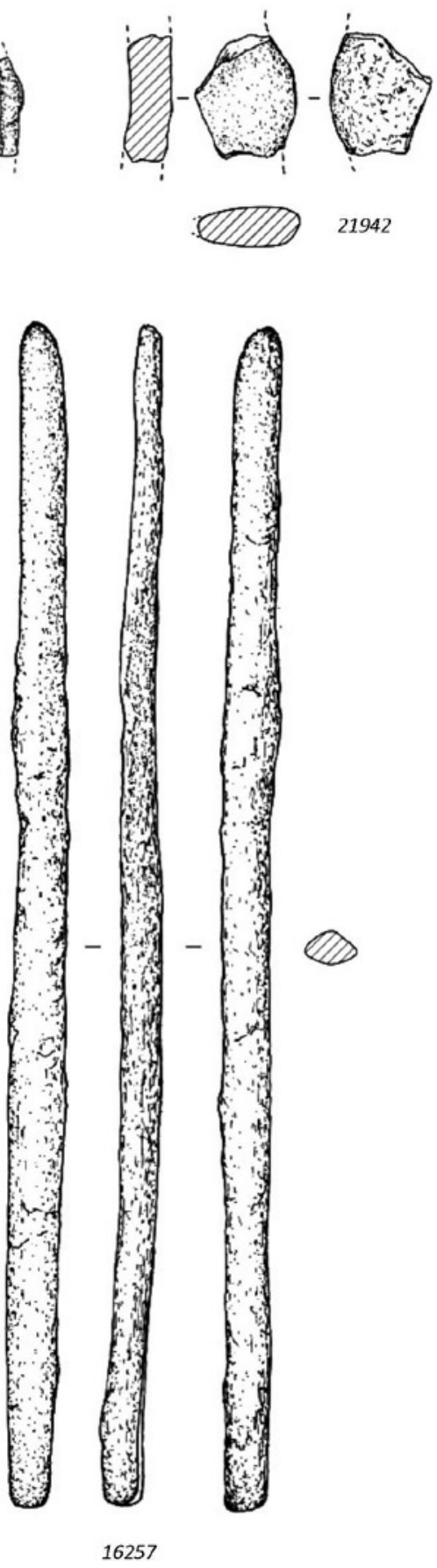
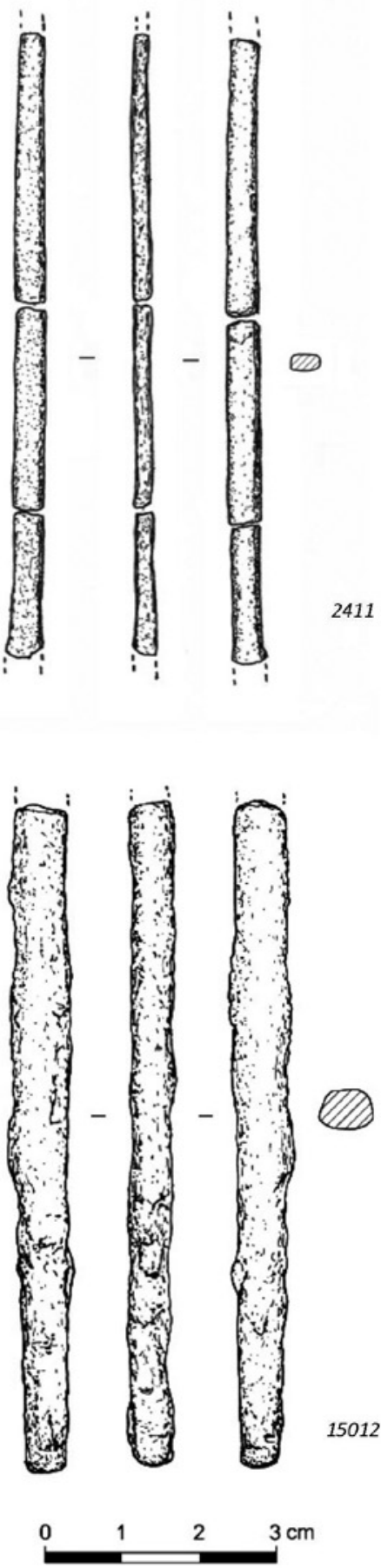

FIG. 8. Restos de trabajo metalúrgico de El Morredón. 
A estos tres metales primarios que forman las aleaciones hay que añadir la presencia de impurezas, elementos que formarían parte de la materia prima y se encuentran en pequeñas cantidades procedentes del mineral procesado y que en conjunto no suelen sumar más del $1 \%$ o el $2 \%$ de la composición. El hierro es el más frecuente debido a que sus óxidos suelen acompañar de forma natural a los minerales de cobre. También el hierro es un indicador de la tecnología de producción y del mineral original procesado. La utilización de minerales ferro-cuprosos -incluidas las calcopiritas- y un mejor dominio de las condiciones de reducción del mineral conducen a una mayor presencia en los metales de la Edad del Hierro. Sin embargo, hay que mantener cierta cautela ya que las pátinas producen un enriquecimiento artificial de sus contenidos que no tiene que ver con estos aspectos tecnológicos sino con la calidad de la limpieza realizada en la superficie de análisis. De nuevo la Fig. 10 nos sirve para confirmar cómo, en general, el hierro disminuye cuanto más se ha conseguido eliminar la corrosión. Cuando analicemos los restos de producción metalúrgica realizaremos algunos comentarios complementarios sobre el nivel de hierro en estas producciones metálicas, aunque lo más frecuente es encontrar contenidos inferiores al $0,5 \% \mathrm{Fe}$.

El resto de elementos $-\mathrm{Ni}, \mathrm{Zn}$, As, Ag y Sbaparecen esporádicamente y sin ningún patrón asociado. Diez contienen níquel en muy baja proporción, con una media del $0,14 \%$. Ocho presentan arsénico en concentraciones bajas, con una media del $0,28 \%$ y una mayor frecuencia en valores menores del 0,1\%. El zinc solo lo identificamos en una cuenta tubular-3688, PA25410- en una proporción del 1,62 \%, al igual que el antimonio que se documenta en una cuenta globular -11365B, PA25414y en baja proporción - $0,22 \%-$, pero en esta pieza ya hemos comentado la poca fiabilidad del análisis. El único elemento no encontrado en ningún análisis es la plata, aunque debemos recordar el elevado nivel de detección del equipo empleado -0,15\%-.

Una visión global muestra que el conjunto arroja una mayoría de piezas de bronce de aleación ternaria de $\mathrm{Cu}-\mathrm{Sn}-\mathrm{Pb}$, comúnmente denominado bronce plomado, aleación que empieza a detectarse de forma significativa a partir del Bronce Final en la península ibérica (Montero-Ruiz, 2010: 175-176). En esta se fabrica todo tipo de piezas: una punta de flecha, objetos de adorno como un botón, anillas y arandelas, anillos, una pulsera, cuentas tubulares
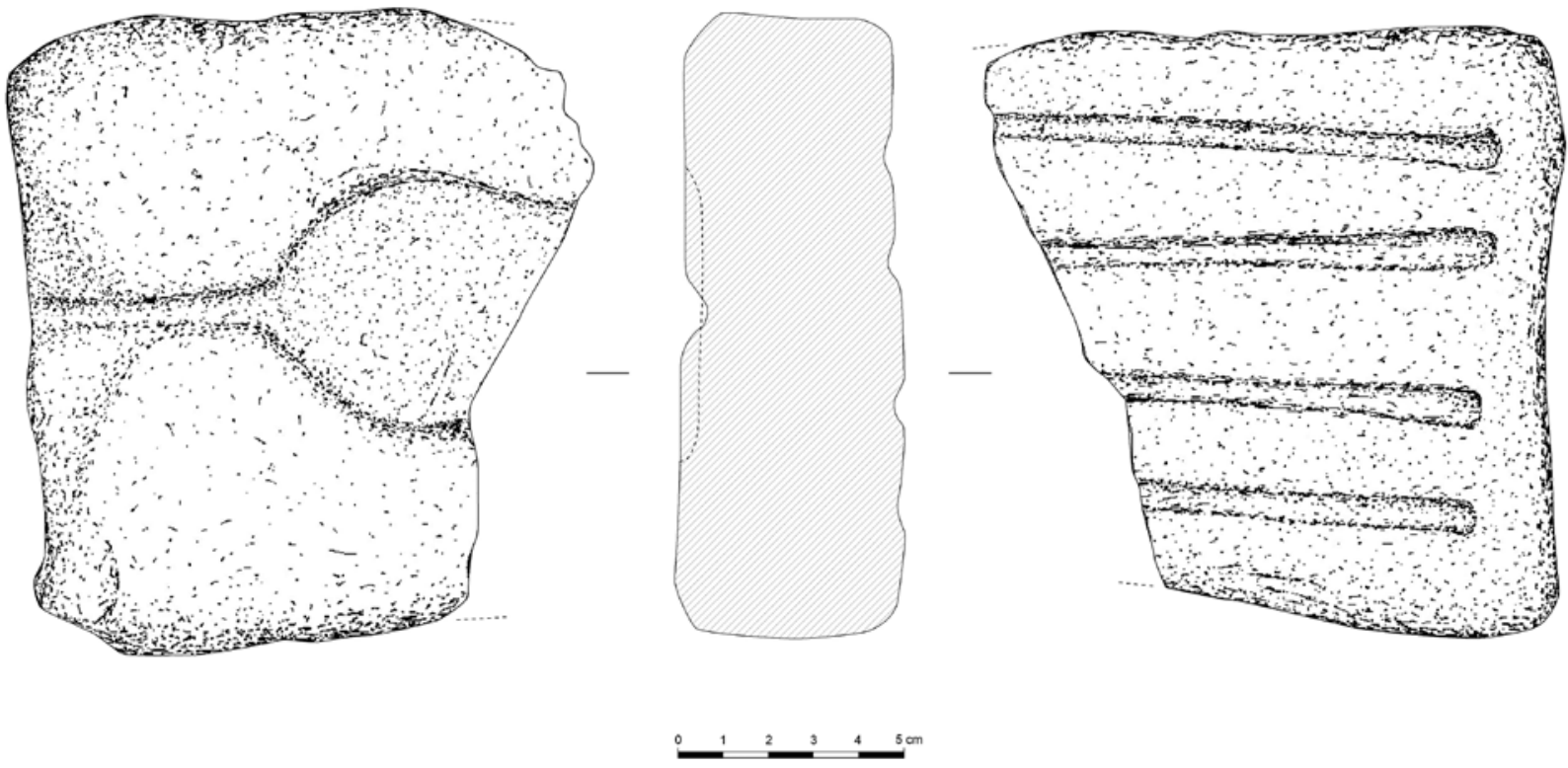

Fig. 9. Molde bivalvo de varillas y broche de cinturón de El Morredón. 
y láminas. En bronce binario $\mathrm{Cu}-\mathrm{Sn}$ hay igualmente distintos tipos, como el hacha de talón, tres puntas de flecha, dos piezas de adorno laminares, dos botones y una espiral.

La tradicional separación entre el bronce ternario y binario según el producto final o técnica de elaboración no se da en este conjunto. La aleación $\mathrm{Cu}-\mathrm{Sn}$ conlleva una mayor dureza, así como una mayor facilidad de trabajo por necesitar una temperatura de fusión menor que el cobre sin aleación o un cobre arsenicado, mientras el cobre plomado da lugar a materiales más blandos y permite la fabricación de piezas más elaboradas y complejas (Montero-Ruiz, 2010: 168-176). Por ello, el bronce binario, se argumenta, sería más adecuado para la fabricación de espadas, puñales o, en general, productos forjados, mientras el ternario sería adecuado para hachas, objetos de adorno, fornituras... (Rovira, 1993: 47). Cabe señalar que la aleación de plomo no buscaría un ahorro en el caro estaño, sino que sus motivaciones serían otras, ya que está atestiguado que la introducción de la aleación de plomo no supone una disminución significativa del estaño, sino del cobre (Rovira, 1993: 47).

En el caso de El Morredón, se observa el uso indistinto de ambas aleaciones para los tipos de piezas identificados, por lo que no se ha constatado en este caso la utilización de una aleación u otra según el producto final, como se ha atestiguado en otros yacimientos (Garcia i Rubert et al., 2007: 151), aunque es cierto que el bronce plomado es la aleación predominante. La única excepción son las puntas de flecha. Por un lado, observamos cierta homogeneidad en la composición de tres de ellas -23184 , 23401 y 19077 - con unos valores entre 91-92,2 \% $\mathrm{Cu}, 6,35-6,69 \% \mathrm{Sn}$ y $0,9-1,9 \% \mathrm{~Pb}$. Es, por tanto, bronce binario bajo en estaño, a diferencia de la cuarta pieza del conjunto -23285-, cuya composición difiere del resto por la concentración de estaño, que alcanza un valor del $12 \%$ (Fig. 10).

\subsection{Restos metalúrgicos}

Además de los dos moldes -varillas y broche de cinturón- descritos en la presentación de los tipos metálicos (Aranda-Contamina et al., 2020) se

Ediciones Universidad de Salamanca / @®ఠ han identificado varios restos semifacturados como las barritas-lingote y el fragmento de lingote plano-convexo. Estos elementos muestran la materia prima empleada en la manufactura de las piezas. Por un lado, el lingote plano-convexo (3131) es de cobre sin estaño aleado, pero tienen la particularidad de incorporar una proporción muy elevada de plomo $\rightarrow 15 \%-$ y por eso lo denominamos lingote de cobre-plomo -se realizaron dos análisis: PA25416 y PA25416B-. Aunque aún nos faltan explicaciones concretas para poder entender por qué ambos elementos circulan ya mezclados, la hipótesis manejada contempla la posibilidad de que tenga relación con la extracción de plata de minerales de cobre argentífero, cuyo subproducto generaría un tipo o variante de copela de cobre-plomo cuyo producto oxidado, al igual que con el litargirio, puede convertirse en un metal que no separa ambos elementos (Rovira y Renzi, 2010). Lo que sí es cierto es que su aparición en el ámbito mediterráneo es cada vez más frecuente en estos momentos de la Primera Edad del Hierro y los dos fragmentos de El Morredón se añaden a la lista de lingotes publicados (Montero-Ruiz et al., 2011). El contenido de plomo es difícil de cuantificar por la distribución segregada de ambos metales, lo que se observa en la diferente proporción medida en zonas distintas del fragmento PA25416 у PA25416в con valores del $74,2 \% \mathrm{~Pb}$ y del $38,8 \% \mathrm{~Pb}$ respectivamente.

$\mathrm{La}$ aleación de este metal $\mathrm{Cu}-\mathrm{Pb}$ con estaño produciría bronces ternarios, como algunos de los objetos comentados en el apartado anterior. Sin embargo, los contenidos de plomo en muchas otras piezas no son tan elevados y deben proceder de otro tipo de materia prima, ya sea de lingotes de cobre puro o del empleo de las barritas-lingote que aparecen ya aleadas. De las cinco identificadas en el yacimiento se analizaron dos. La identificada con el número PA25402 pertenece a la fase del bronce final y es un bronce binario, como es habitual en la metalurgia del periodo. La pieza PA25406 de la Edad del Hierro incorpora ya plomo de manera moderada $-6 \%$-. A partir de estas barritas-lingote se pudieron fabricar otra serie de objetos que presentan proporciones semejantes en la composición. 


\begin{tabular}{|c|c|c|c|c|c|c|c|c|c|c|c|c|}
\hline N. ${ }^{\circ}$ ANÁLISIS & FASE & N.o INV. & $\mathrm{Fe}$ & $\mathrm{Ni}$ & $\mathrm{Cu}$ & $\mathrm{Zn}$ & As & $\mathrm{Ag}$ & Sn & $\mathrm{Sb}$ & $\mathrm{Pb}$ & $\mathrm{LE}$ \\
\hline PA25408 & II & 6379 & ND & ND & 82,3 & ND & $\mathrm{ND}$ & ND & 6,51 & $\mathrm{ND}$ & 11,2 & ND \\
\hline PA25402 & II & 15012 & 0,06 & ND & 90,9 & ND & 0,09 & $\mathrm{ND}$ & 8,86 & $\mathrm{ND}$ & 0,03 & ND \\
\hline PA25409 & II & 15013 & 0,25 & ND & 90,9 & ND & 0,2 & ND & 8,03 & $\mathrm{ND}$ & 0,48 & ND \\
\hline PA24438A & II & 54272 & 0,1 & ND & 97,7 & ND & $\mathrm{ND}$ & $\mathrm{ND}$ & 2,09 & $\mathrm{ND}$ & 0,09 & ND \\
\hline РА24438в & II & 54272 & 0,19 & ND & 93,9 & ND & 0,06 & ND & 5,75 & $\mathrm{ND}$ & 0,12 & ND \\
\hline PA25413 & II & $11365 \mathrm{~A}$ & 0,16 & ND & 91,2 & ND & $\mathrm{ND}$ & $\mathrm{ND}$ & 7,81 & ND & 0,6 & ND \\
\hline PA25414 & II & 11365 в & 0,1 & ND & 34,1 & ND & 0,18 & ND & 17,3 & 0,22 & 0,15 & ND \\
\hline PA25415 & III & 2411 & 0,13 & ND & 80,3 & $\mathrm{ND}$ & $\mathrm{ND}$ & ND & 13,3 & ND & 6,3 & ND \\
\hline PA25404 & III & 2412 & 0,53 & ND & 65,3 & ND & $\mathrm{ND}$ & $\mathrm{ND}$ & 9,02 & ND & 25,1 & ND \\
\hline PA25405 & III & 2470 & 0,94 & ND & 85,8 & ND & ND & ND & 10,6 & ND & 2,68 & ND \\
\hline PA25416 & III & 3131 & 1,68 & ND & 24,1 & ND & $\mathrm{ND}$ & $\mathrm{ND}$ & $\mathrm{ND}$ & ND & 74,2 & ND \\
\hline PA25416B & III & 3131 & 0,57 & 0,09 & 60,6 & ND & $\mathrm{ND}$ & $\mathrm{ND}$ & $\mathrm{ND}$ & ND & 38,8 & ND \\
\hline PA25403 & III & 3399 & 0,81 & $\mathrm{ND}$ & 84,2 & $\mathrm{ND}$ & $\mathrm{ND}$ & $\mathrm{ND}$ & 7,88 & ND & 7,15 & ND \\
\hline PA25417 & III & 3400 & 4,09 & 0,13 & 54,9 & ND & $\mathrm{ND}$ & ND & 12,7 & ND & 28,2 & ND \\
\hline PA25410 & III & 3688 & 0,59 & ND & 87,3 & 1,62 & $\mathrm{ND}$ & $\mathrm{ND}$ & 4,37 & ND & 6,16 & ND \\
\hline PA25406 & III & 16257 & 0,44 & 0,1 & 84,8 & ND & $\mathrm{ND}$ & ND & 7,91 & ND & 6,75 & ND \\
\hline PA25419 & III & 18851 & 1,18 & ND & 86,4 & ND & $\mathrm{ND}$ & $\mathrm{ND}$ & 9,84 & ND & 2,54 & ND \\
\hline PA25425 & III & 19077 & 0,27 & ND & 91,0 & ND & 0,3 & ND & 6,35 & ND & 1,9 & ND \\
\hline PA25420 & III & 19078 & 0,53 & ND & 88,3 & ND & 0,91 & $\mathrm{ND}$ & 3,49 & $\mathrm{ND}$ & 6,82 & ND \\
\hline PA25430 & III & 19167 & 1,25 & ND & 82,2 & ND & ND & ND & 6,04 & ND & 10,5 & ND \\
\hline PA25427 & III & 19168 & 1,21 & ND & 97,1 & ND & $\mathrm{ND}$ & ND & 1,36 & ND & 0,2 & ND \\
\hline PA25426 & III & 20039 & 1,29 & ND & 88,1 & $\mathrm{ND}$ & $\mathrm{ND}$ & ND & 5,35 & ND & 5,27 & ND \\
\hline PA25432 & III & 21020 & 2,44 & 0,11 & 14,7 & ND & ND & ND & 2,37 & ND & 2,17 & 78,1 \\
\hline PA25434B & III & 21941 & 0,29 & ND & 88,0 & $\mathrm{ND}$ & 0,15 & $\mathrm{ND}$ & 10,8 & ND & 0,52 & ND \\
\hline PA25421 & III & 21942 & 0,53 & ND & 60,8 & ND & ND & ND & $\mathrm{ND}$ & $\mathrm{ND}$ & 38,7 & ND \\
\hline PA25433 & III & 22225 & ND & 0,17 & 78,0 & ND & $\mathrm{ND}$ & ND & $\mathrm{ND}$ & ND & 21,8 & ND \\
\hline PA25411 & III & 23398 & 0,91 & ND & 83,7 & $\mathrm{ND}$ & $\mathrm{ND}$ & $\mathrm{ND}$ & 9,88 & ND & 5,54 & ND \\
\hline PA25423P & sup. & 22749 & 1,81 & ND & 86,3 & ND & $\mathrm{ND}$ & ND & 10,3 & ND & 1,68 & ND \\
\hline PA25424 & sup. & $22749_{A}$ & 5,19 & 0,2 & 31,3 & ND & ND & ND & 11,8 & $\mathrm{ND}$ & 2,45 & 48,9 \\
\hline PA 5428 & sup. & 23184 & 0,25 & ND & 92,0 & ND & $\mathrm{ND}$ & ND & 6,69 & ND & 0,9 & ND \\
\hline PA25401 & sup. & 23284 & 0,59 & 0,08 & 87,1 & $\mathrm{ND}$ & $\mathrm{ND}$ & $\mathrm{ND}$ & 7,21 & $\mathrm{ND}$ & 5,02 & ND \\
\hline PA25407 & sup. & 23285 & 0,23 & ND & 87,5 & $\mathrm{ND}$ & 0,08 & $\mathrm{ND}$ & 12,0 & $\mathrm{ND}$ & 0,13 & ND \\
\hline PA25412 & sup. & 23286 & 0,4 & 0,09 & 84,5 & $\mathrm{ND}$ & $\mathrm{ND}$ & $\mathrm{ND}$ & 3,7 & $\mathrm{ND}$ & 11,3 & ND \\
\hline PA25422 & sup. & 23399 & ND & 0,18 & 67,2 & ND & $\mathrm{ND}$ & ND & 8,96 & $\mathrm{ND}$ & 23,7 & ND \\
\hline РА 25429 в & sup. & 23400 & 0,48 & $\mathrm{ND}$ & 70,4 & $\mathrm{ND}$ & $\mathrm{ND}$ & $\mathrm{ND}$ & 10,9 & $\mathrm{ND}$ & 18,2 & ND \\
\hline PA25431P & sup. & 23401 & 0,26 & ND & 92,2 & $\mathrm{ND}$ & $\mathrm{ND}$ & $\mathrm{ND}$ & 6,46 & $\mathrm{ND}$ & 0,97 & ND \\
\hline PA25418P & - & MB113 & 0,26 & 0,26 & 75,3 & ND & 0,33 & ND & 13,7 & ND & 10,2 & ND \\
\hline
\end{tabular}

FIG. 10. Análisis por fluorescencia de rayos X (XRF). Los análisis se expresan como porcentaje en peso (\%) de cada uno de los elementos detectados $(N D=$ no detectado). En el caso de la plata $(A g)$ y antimonio $(S b)$ el límite de detección es del 0,15\%, para el resto de elementos se sitúa en el 0,02\%. Los márgenes de error en las medidas son de alrededor del $1 \%$ para los elementos mayoritarios, entre el $2 \%$ y $5 \%$ para los elementos minoritarios y pueden alcanzar el $40 \%$ para los elementos de composición inferior al 0,1\%. LE = elementos ligeros (número atómico <20). 
Si de los lingotes $\mathrm{Cu}-\mathrm{Pb}$ podemos afirmar que son objetos importados de larga distancia tal y como sugieren los datos hasta ahora conocidos con origen en el s peninsular -con procedencia del plomo de las minas de Linares y Gador- (Montero-Ruiz et al., 2014), sobre el origen de las barritas-lingote no podemos concretar y todas las opciones son viables, desde importaciones lejanas a la preparación en el propio taller del poblado.

Los restos de fundición o goterones son pequeños fragmentos de metal que se pierden en la colada o preparación del metal y serían indicativos de las aleaciones manejadas en la manufactura de los objetos. Los dos restos estudiados reflejan composiciones distintas. Uno de ellos -PA25421- correspondería al metal de los lingotes $\mathrm{Cu}-\mathrm{Pb}$ y el otro -PA25434B- al de un bronce binario.

También se han recuperado pequeños fragmentos de escoria, que pueden corresponder a la reacción térmica de las paredes del crisol ya que se componen de una gran parte de metal, con contenidos de hierro elevados, pero no tanto como en las escorias de reducción de mineral. La composición refleja la presencia de los tres elementos aleados $-\mathrm{Cu}, \mathrm{Sn}, \mathrm{Pb}-$, pero sus proporciones no necesariamente son coincidentes con las del metal procesado en el crisol.

Todos estos elementos, aunque escasos, son indicadores de que principalmente en la Fase III -Primera Edad del Hierro- el poblado de El Morredón contaba con un taller metalúrgico en el que se produjeron objetos con distintas aleaciones. Este taller no es incompatible con la llegada de productos manufacturados externos y sobre todo de materia prima.

\subsection{Estudio comparativo}

En el valle del Ebro se han realizado pocos análisis y en pocos yacimientos, especialmente de los periodos cronológicos que aquí interesan -Bronce Final y Primera Edad del Hierro-. Aun así, merece la pena comentar el panorama actual ya que nos puede servir como indicador de futuras actuaciones.
Los análisis de composición realizados en las dos hachas de talón localizadas en el propio El Morredón (García-Arilla, 2015) y el broche de cinturón procedente de Burrén (García-Arilla y Mesa, 2016) dan como resultado bronces binarios con concentraciones similares: las hachas de talón presentan $87,3-88,4 \% \mathrm{Cu}$ y $11,6-12,7 \% \mathrm{Sn}$ respectivamente; mientras el broche un $90 \% \mathrm{Cu}$ y 9,9\% Sn. Se asemejan, por tanto, a los porcentajes que hemos detectado en el propio yacimiento que estudiamos, aunque los valores de $\mathrm{Sn}$ sean predominantemente más bajos en el conjunto analizado procedente de las excavaciones. Estos análisis de El Morredón se obtuvieron con un microscopio electrónico de barrido en el Instituto de Historia del csic por lo que no pudieron cuantificarse elementos minoritarios. Las tres piezas se re-analizaron con el espectrómetro portátil en el Museo de Zaragoza y los resultados obtenidos (Fig. 10) validan el mayor contenido en estaño de las hachas de talón y una anilla, aunque el broche de cinturón ha proporcionado un contenido algo más bajo de estaño. Las hachas de talón llevan una pequeña cantidad de arsénico -As- $\mathrm{y}$, además, las tres ofrecen también bajas cantidades de plomo.

Siguiendo el curso del Huecha, contamos con los análisis del Alto de la Cruz de Cortes y de las cercanas necrópolis de La Atalaya y La Torraza (Maluquer et al., 1990: 151-172). Se realizaron en los Laboratorios del Servicio de Espectroscopia de la Universidad de Barcelona mediante una combinación de técnicas - OES, AA y XRF- para cuantificar los distintos elementos. Compararemos solo los elementos mayoritarios de la aleación - $\mathrm{Cu}$, $\mathrm{Sn}$ y $\mathrm{Pb}-$ ya que entre los minoritarios no se buscó el arsénico -As- o el antimonio - $\mathrm{Sb}$ - y en la plata se indica mayoritariamente si está por encima o por debajo de las 200 ppm. Para esta comparación es necesario normalizar al $100 \%$ los datos publicados ya que en la mayoría de los casos el porcentaje de la suma de los tres elementos aleados no alcanza el $90 \%$, lo que indica que las muestras procesadas llevaban gran cantidad de corrosión, como atestiguan la presencia de sílice y aluminio entre los elementos detectados. Del Alto de la Cruz se muestrearon 49 piezas en bronce de las distintas fases de hábitat. $\mathrm{El} \mathrm{Cu}$ 
aparece con una media del $86,5 \%$, el estańo tiene una media del 11,9\% y el plomo del 1,5\%. Estos valores pueden estar afectados por el efecto pátina ya que hemos comprobado que las muestras analizadas incluían muchos productos de corrosión. Hay varias piezas que superan el $20 \%$ Sn y una llega al $39 \%$. También aparecen algunas piezas de cobre sin alear como un remache, un asador o un fragmento de colador, además de un fragmento de lingote; este tipo de metal sin alear no se ha registrado en los objetos de El Morredón. La mayoría son bronces binarios con proporciones de plomo inferiores al $2 \%$, y solo once $-22 \%$ - serían bronces plomados pero con predominio de los contenidos bajos $-<5 \%$ - En este punto se encuentra una de las grandes diferencias de ambos conjuntos: los valores más elevados de plomo en el yacimiento de Fréscano.

De la necrópolis de La Atalaya se analizaron catorce piezas con proporciones muy similares de cobre, estaño y plomo a las recogidas en el Alto de la Cruz, y un solo caso de aleación de bronce plomado. Parecida situación encontramos en La Torraza, con catorce muestras, aunque presenta un número mayor de piezas que podrían considerarse bronce plomado -tres superan el $2 \%$ de concentración de $\mathrm{Pb}$ después de la normalización al 100 \%- (Maluquer et al., 1990: 162-170).

Los antecedentes de la metalurgia del Bronce Final del valle del Huecha se localizan en la cercana Muela de Borja, intensamente poblada durante la Edad del Bronce con poblados importantes como
Moncín o la cueva de Majaladares, que presentan fundamentalmente bronces binarios, salvo dos piezas con plomo de Moncín, un cuchillo de la Fase IIA del final de Cogotas I -5,6 \% Pb- y una punta de flecha de la Fase IIE -2 \% Pb- (Aguilera, 2017).

Ya fuera del valle del Huecha, contamos con pocos datos en el valle medio del Ebro. Es el caso de los análisis inéditos realizados dentro del proyecto "Arqueometalurgia de la Península Ibérica" de algunos materiales metálicos del Cabezo Morrudo (Fuentes de Ebro), poblado de la Primera Edad del Hierro (Fig. 11). Se trata de seis piezas de distinta tipología con una composición mayoritariamente de cobre con una media del $80 \%$. Dos son bronce binario $\mathrm{Cu}-\mathrm{Sn}$ con unos valores de estaño entre $10,7 \%$ y $12,6 \%$, y tres aleaciones de bronce plomado con concentraciones de plomo entre 2,98\% y 6,29 \%. El Cabezo Morrudo, por tanto, y a pesar de la pequeña muestra analizada, presenta unos valores similares a los ofrecidos por el conjunto del valle del Huecha.

Más alejadas de nuestra zona de influencia, pero en áreas cercanas del noreste, encontramos mayor predominio de cobre plomado en el Calvari del Molar, en Tarragona. Allí, de 25 piezas analizadas, quince son bronces plomados y diez bronces binarios (Montero-Ruiz et al., 2012: 173-174), con valores medios de estaño del $11,4 \%$ y $11,7 \%$ y de plomo del $6,2 \%$, por lo que serían aleaciones menos plomadas que en El Morredón. Otro de los grandes centros metalúrgicos de la región sería Sant Jaume-Màs d'en Serrà, donde está atestiguada una

\begin{tabular}{|c|c|c|c|c|c|c|c|c|c|c|c|c|}
\hline N. ${ }^{\circ}$ ANÁLISIS & Овјето & $\begin{array}{c}\text { N. }{ }^{\circ} \\
\text { INVENTARIO }\end{array}$ & $\mathrm{Fe}$ & $\mathrm{Ni}$ & $\mathrm{Cu}$ & $\mathrm{Zn}$ & As & $\mathrm{Ag}$ & Sn & $\mathrm{Sb}$ & $\mathrm{Pb}$ & LE \\
\hline РА 24439 B & hacha de cubo y una anilla & 48159 & 0,98 & 0,35 & 85,3 & ND & ND & ND & 12,6 & ND & 0,57 & ND \\
\hline PA24440 & cilindro con cincel hierro & 48160 & 4,48 & $\mathrm{ND}$ & 89 & ND & ND & ND & 0,23 & ND & 6,29 & ND \\
\hline PA24441 & fíbula doble resorte & 48189 & 0,29 & ND & 87,6 & ND & ND & ND & 9,14 & ND & 2,98 & ND \\
\hline РА24442B & fíbula doble resorte & 48190 & 0,14 & ND & 89,7 & ND & ND & ND & 5,33 & ND & 4,8 & ND \\
\hline PA24443A & lámina & 48199 & 0,06 & ND & 89 & ND & ND & ND & 10,7 & ND & 0,17 & ND \\
\hline РА24443в & lámina con perforación & 48199 & 0,27 & $\mathrm{ND}$ & 91,9 & ND & 0,04 & ND & 7,66 & ND & 0,1 & ND \\
\hline PA24444P & fíbula botón & 48194 & 30,63 & ND & 23,1 & ND & 0,03 & ND & 0,03 & ND & ND & 46,1 \\
\hline
\end{tabular}

Fig. 11. Análisis de los materiales del poblado de la Primera Edad del Hierro de Cabezo Morrudo (Fuentes de Ebro, Zaragoza). Los análisis se expresan como porcentaje en peso (\%) de cada uno de los elementos detectados (ND = no detectado). 
notable actividad metalúrgica que incluía el empleo de lingotes de forma plano-convexa, en algunos casos de aleación de $\mathrm{Cu}-\mathrm{Pb}$. En este caso es más abundante la presencia de bronces binarios, con altas medias de estaño -14-15\%-, superior al área del Molar, mientras las tasas de plomo de los bronces ternarios -solo 9 piezas de 40 analizadas- sufren grandes oscilaciones con una media del 4,96\% (Garcia i Rubert et al., 2007).

\section{Consideraciones finales}

Partiendo del análisis de los posibles recursos naturales de las proximidades; de la capacidad de obtención de materias primas; del propio trabajo metalúrgico; de las características del conjunto metálico en relación con el contexto del valle del Huecha y del valle medio del Ebro, y, finalmente, de sus evidentes afinidades, según la tipología y composición de determinados objetos, con las dos corrientes metalúrgicas peninsulares: la atlántica y la mediterránea, intentaremos averiguar algunas de las circunstancias y peculiaridades del desarrollo y evolución de la metalurgia de El Morredón.

El valle medio del Ebro y el conjunto de la depresión del Ebro en general, salvo en el caso del estańo de cuya presencia prácticamente no existen evidencias, es un territorio con recursos minerales accesibles desde la Prehistoria, como bien recoge el trabajo de Rodríguez de la Esperanza (2005: $37-$ 42). Son significativos el cobre, la plata y el oro, e incluso es abundante y bien documentado el mineral de hierro en las sierras del Moncayo.

Ante la ausencia de evidencias directas de las vías de obtención de la materia prima para elaborar el metal en el propio yacimiento, adquieren especial importancia las barritas-lingote y el fragmento de lingote plano-convexo de cobre plomado sin estaño. Es factible que estos restos metalúrgicos llegasen por vías de intercambio y/o comercio, o incluso ya productos finales tal como se ha documentado en el noreste de la península entre los ss. VII-VI a. C. en yacimientos como el Calvari del Molar (Montero-Ruiz et al., 2012).

Es especialmente interesante el caso del lingote plano-convexo realizado en cobre plomado, junto a otro fragmento semejante y un goterón de fundición de similar composición. Su aparición parece indicar que el comercio de materias primas es tan intenso que requiere medir cuantitativamente el volumen de metal intercambiado, lo que no es posible con el mero trueque de minerales. Asimismo, supone la optimización del transporte del metal y permite la especialización en la manufactura de los objetos finales por quienes reciben estos lingotes, en aquellas zonas pobres en materia prima o donde solo está documentada la fase de producción (Montero-Ruiz et al., 2010-2011: 99-100, 108-109). En El Morredón queda atestiguada la llegada de cobre plomado de esta forma, al que se le añadiría el estaño para formar la aleación más habitual del yacimiento, $\mathrm{Cu}-\mathrm{Sn}-\mathrm{Pb}$.

Lingotes similares se localizan en toda la geografía peninsular de forma habitual a partir de la primera mitad del I milenio, especialmente durante los ss. vir y vi a. C., por el No peninsular, pero también en el área mediterránea (Gómez Ramos, 1993; Montero-Ruiz et al., 2010-2011), mientras que los ejemplares detectados en el valle medio del Ebro son escasos. Contamos con los lingotes del Alto de la Cruz en Navarra, de Kutzkumendi en Vitoria y en Tossal Redó en Teruel (Gómez Ramos, 1993), a los que se suma el inventariado en El Morredón. Habitualmente su composición es cobre sin alear, con baja presencia de otros elementos, aunque en ocasiones incorporan plomo ${ }^{3}$. Un estudio sobre este tipo identificó once ejemplares en los que el plomo superaba el $1 \%$, con siete de ellos por encima del $10 \% \mathrm{~Pb}$, distribuidos en el área mediterránea,

3 El estaño aparece como impureza en ocasiones, pero descartamos su incorporación como aleación puesto que los dos únicos ejemplares son análisis antiguos de los lingotes procedentes del Alto de la Cruz de Cortes de Navarra y los de Kutzkumendi. Un análisis más reciente de los dos lingotes del Alto de la Cruz mostró la ausencia de estaño (Maluquer et al., 1990: 158), por lo que serían lingotes de cobre en el caso de la muestra PIP-199 o ligeramente plomado la 
en poblados como Can Roqueta, Sant Jaume Mas d'en Serrà, Tossal del Mortorum y Aljubs (Montero-Ruiz et al., 2010-2011: 109).

Significativos en cuanto a su movimiento son los resultados del estudio de isótopos de plomo de los restos de El Calvari de El Molar, en Tarragona (Montero-Ruiz et al., 2012), que muestran su procedencia de la zona de Linares en Jaén, a pesar de la existencia de importantes recursos locales de cobre, plomo y plata (Rafel et al., 2014; Soriano y Hunt, 2018). De hecho, los restos de El Calvari parecen señalar su papel principal en el control y gestión de los trabajos mineros, especialmente vinculados con la obtención de plomo. Ello lleva a concluir a los autores la existencia de circuitos comerciales establecidos entre el sur peninsular, mayoritariamente desde las minas de Linares y en menor medida de Almería, y el área de la desembocadura del Ebro en el s. viI y primera mitad del vi a. C., quedando por definir cómo se produciría en el resto del noreste (Montero-Ruiz et al., 2012: 181).

En cuando al estaño, como hemos visto, no hay recursos en las áreas más próximas, sino que los yacimientos más explotados por su riqueza se encontraban en Galicia, N de Portugal, Cantabria, Salamanca, Zamora y Cáceres. No hay constancia en el registro arqueológico del poblado que estudiamos de cómo sería su introducción.

Atendiendo a los restos localizados, cabe afirmar que se realizaría trabajo metalúrgico en el propio yacimiento. Es difícil confirmar si hubo un proceso de transformación del mineral o solo de producción, especialmente ante la ausencia de estructuras claras dedicadas a estos menesteres. A pesar de la identificación de varias estructuras de combustión en las excavaciones, la dispersión de los elementos metalúrgicos impide asociarlos entre ellos. Igualmente,

muestra PIP-198. No es de extrañar puesto que esta diferencia entre análisis antiguos y recientes se ha atestiguado en otros yacimientos (Montero-Ruiz et al., 2010-2011: 109), y además no hay testimonios claros de lingotes de bronce en la Prehistoria mediterránea o europea. no podemos especificar aspectos como el proceso a través del cual se producirían las aleaciones ${ }^{4}$.

En la organización de la producción metalúrgica se desarrollan distintas actividades que pueden realizarse independientemente, en especial las de extracción minera, la reducción del mineral a metal y la producción de objetos. Determinar cómo y dónde se producen estas actividades requiere evidencias directas como la localización de lugares de producción, teniendo en cuenta su llegada por la existencia de redes de intercambio/comercio ante la ausencia de evidencias estructurales, así como por la aparición de lingotes como forma de acumulación y transporte (Montero-Ruiz y Rovira, 2010: 23-26).

Una de las evidencias de actividades de producción más relevantes son las escorias, de transformación y de producción. En El Morredón se localizaron varias escorias mixtas de $\mathrm{Cu}-\mathrm{Sn}-\mathrm{Pb}$ de pequeño tamaño y una escoria de hierro. Podrían ser debidas a la producción, puesto que la elaboración de productos está atestiguada por otros restos como los goterones de fundición o el molde de arenisca de varillas y broche de cinturón. Igualmente, algunos materiales líticos podrían estar relacionados con esta actividad productiva. Uno de ellos es un afilador, elemento necesario para la vida útil del objeto y para el acabado final en la manufactura de piezas con filo.

Para finalizar, debemos señalar que la metalurgia de El Morredón se debe interpretar teniendo en cuenta los cambios que se producen a partir del Bronce Final, que da lugar a dos tradiciones metalúrgicas en la península ibérica: la atlántica y la mediterránea. Entre estos cambios, destaca el

4 Como demostraba Rovira (2007), a pesar de los ríos de tinta escritos sobre la obtención de bronce, es difícil decantarse por una de las tres hipótesis en la fabricación de útiles en este metal: la aleación de $\mathrm{Cu}$ y $\mathrm{Sn}$-a partir de la Primera Edad del Hierro-, la cementación de bronce con casiterita-Bronce Final-y la co-reducción de minerales de $\mathrm{Cu}$ y $\mathrm{Sn}-$ Bronce Antiguo- sin recurrir a técnicas analíticas como la microscopía electrónica de barrido-SEM-EDX-, que permite observar las distintas fases minerales que constituyen la estructura de las escorias a la vez que la composición química de dichas fases. 
incremento de aleaciones plomadas y el aumento de su tasa media, aunque su reflejo en el panorama peninsular es irregular. Las aleaciones se van haciendo más abundantes en plomo en los periodos más recientes, como se observa en el área mediterránea. Algunos territorios presentan altos niveles de plomo como es el caso del noroeste y la parte occidental de la cuenca del Duero, mientras que en otros como Cataluña y Levante se da la situación inversa (Rovira, 2004: 32). Por ello, en la producción metalúrgica de bronce durante la Edad del Hierro se atribuye la presencia de bronces con alta carga de plomo a conexiones con la metalurgia gallega y la ultrapirenaica de la fachada atlántica.

También en las tasas medias de estaño se observan diferencias territoriales. Mientras zonas como la Meseta Sur, Levante y Andalucía destacan por el bajo nivel de estaño en las aleaciones (con menos del $8 \%$ de estaño), los que se denominan 'bronces pobres' (Rovira, 1993: 47-49), las áreas más ricas en estaño de la península, Galicia, el $\mathrm{N}$ de Portugal, Salamanca, Zamora y Extremadura, muestran un porcentaje más elevado, lo que señalaría la explotación de estos recursos locales (Rovira, 2004: 32).
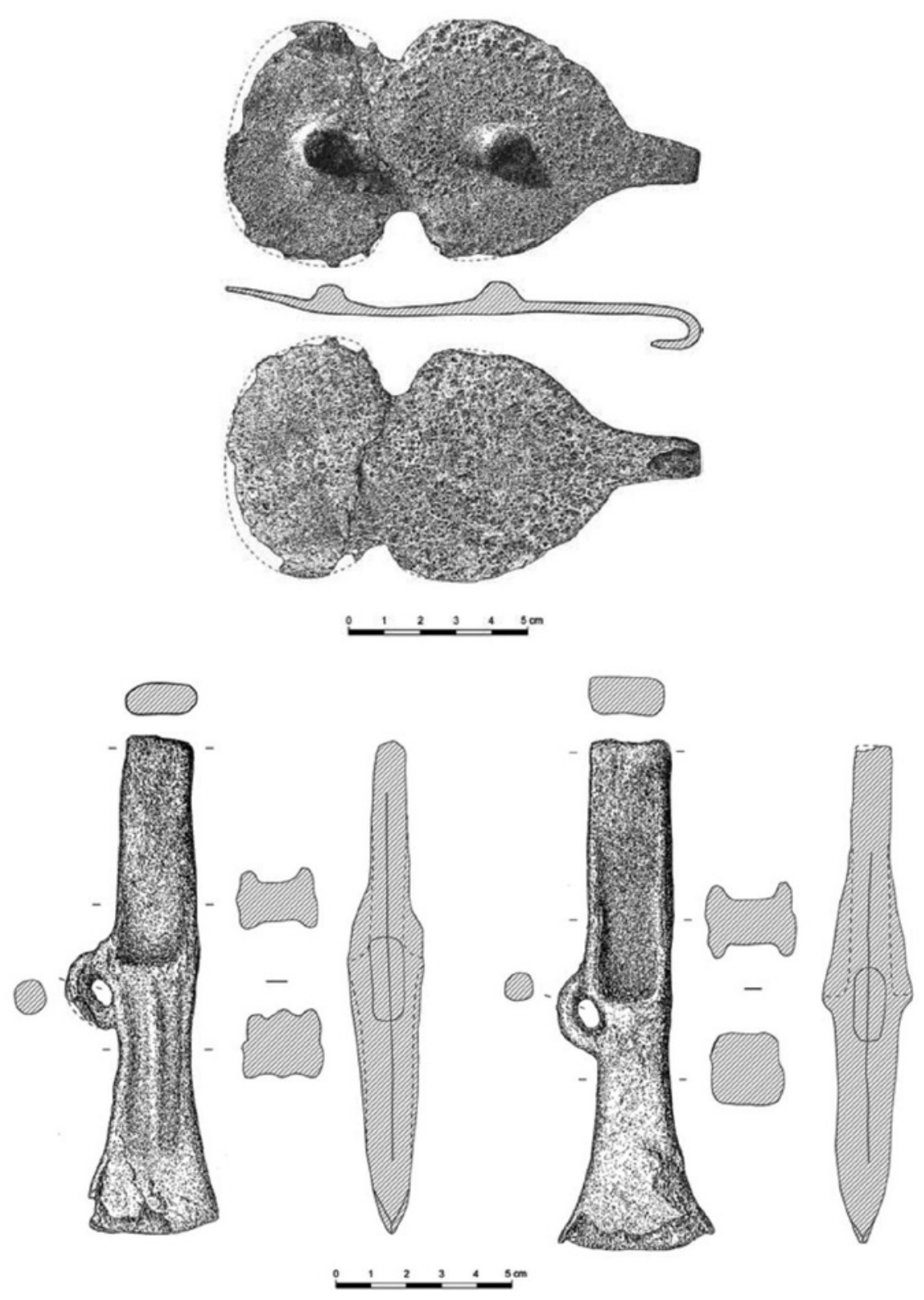

FIG. 12. Repertorio de materiales en el valle del Huecha de influencia atlantica: broche de cinturón procedente de Burrén (García-Arilla y Mesa, 2016: 34, fig. 2) y hachas de talón procedentes de El Morredón (García-Arilla, 2015: 14, fig. 2).
En el caso de El Morredón, se observan más conexiones con las áreas de la Meseta Sur, Cataluña, Levante o Andalucía, al presentar un alto número de muestras con niveles bajos de Sn y niveles medios de $\mathrm{Pb}$, en contraste con las zonas más plomadas. La pobreza de estaño puede deberse a un 
limitado suministro del metal o a su elevado coste, que obligase a un reciclado (Rovira, 1993: 50-51). Tipológicamente, el colgante de carnero localizado en El Morredón hace unas décadas (Aguilera, 2013) remite igualmente a relaciones mediterráneas claramente documentadas mediante la aparición de numerosos objetos procedentes de intercambios con las zonas costeras del Mediterráneo (Rodanés y Picazo, 2014, 2018). No obstante, otras piezas son de influencia indiscutible del Bronce Atlántico o el mundo centroeuropeo, como las tres hachas de talón o los broches de cinturón de tipo céltico de los que conservamos el molde de El Morredón y un ejemplar del cercano yacimiento de Burrén (Fig. 12) (García-Arilla, 2015; García-Arilla y Mesa, 2016; Aranda-Contamina et al., 2020). Por tanto, lo que observamos es una metalurgia que se desarrollaría en el propio poblado, pero en la que confluirían las tradiciones mediterránea y atlántica a través de mecanismos de intercambio o comercio que hoy en día son difíciles de precisar.

\section{Bibliografía}

Aguilera, I. (1995): "El poblamiento celtibérico en el área del Moncayo". En Burillo, F. (coord.): Poblamiento celtibérico. III Simposio sobre los celtíberos (Daroca, 1991). Zaragoza: IFC, pp. 213-233.

Aguilera, I. (2013): "La sepultura número 13 y su vaso vertedor con cabeza de carnero". En Beltrán, M.: Azaila. Estado de la cuestión en el año 2013. Caesaraugusta, 83. Zaragoza, pp. 180-187.

Aguilera, I. y Royo, J. I. (1978): "Poblados hallstáticos del valle de La Huecha. Contribución al estudio de la 1. ${ }^{a}$ Edad del Hierro en la Cuenca del Ebro", Cuadernos de Estudios Borjanos, II, pp. 9-44.

Álvarez Clanijo, P. y Pérez Arrondo, C. L. (1987): La cerámica excisa de la Primera Edad del Hierro en el Valle Alto y Medio del Ebro. Col. Historia, 8. Logrońo: Instituto de Estudios Riojanos.

Álvarez Gracia, A. (1992-1993): "El Bronce Final-Hierro I en el Bajo Aragón y sus relaciones con el valle medio del Ebro". En Segundos Encuentros de Prehistoria Aragonesa (Caspe-Zaragoza, 1986). Bajo Aragón Prehistoria, IX-X. Zaragoza: IfC-CECBA, pp. 51-62.

Ediciones Universidad de Salamanca / @®ఠ
Aranda-Contamina, P.; Lorenzo, J. I. y Rodanés, J. M. ${ }^{a}$ (2016): "Estructuras de ocupación de la ladera sudoeste de El Morredón (Fréscano, Zaragoza)". En Lorenzo, J. I. y Rodanés, J. M. (eds.): Actas I Congreso de Arqueología y Patrimonio Aragonés (2015). Zaragoza, pp. 179-187.

Aranda-Contamina, P.; Montero, I.; Rodanés, J. M. y Lorenzo, J. I. (2020): "Materiales metálicos del Bronce Final y Primera Edad del Hierro del poblado de El Morredón (Fréscano, Zaragoza). Estudio tipológico”. En Lorenzo, J. I. y Rodanés, J. M. (eds.): Actas III Congreso de Arqueología y Patrimonio Aragonés (2019). Zaragoza, pp. 139-148.

Aranda-Contamina, P. y Rodanés, J. M. a (2019): "La decoración excisa como indicador de procesos de interacción e intercambio durante el Bronce Final en el valle medio del Ebro. Reflexiones a partir de nuevos hallazgos y dataciones absolutas", Trabajos de Prehistoria, 76 (1), pp. 84-101.

Aranda-Contamina, P.; Rodanés, J. M. y Lorenzo, J. I. (2018): "Las fases de ocupación de El Morredón (Fréscano, Zaragoza)". En Lorenzo, J. I. y RodANÉs, J. M. (eds.): Actas II Congreso de Arqueología y Patrimonio Aragonés. Zaragoza, t. I, pp. 139-148.

Armendáriz, J. A. (1995-1996): "Poblado de Las Eretas (Berbinzana): campañas de 1994, 1995 y 1996", Trabajos de Arqueología Navarra, 12, pp. 298-303.

Armendáriz, J. A. (2008): De aldeas a ciudades: el poblamiento durante el primer milenio a. C. en Navarra. Pamplona: Institución Príncipe de Viana.

Castiella, A. y Sesma, J. (1988-1989): "Piezas metálicas de la Protohistoria. Navarra: armas", Zephyrus, XLI-XLII, pp. 383-404.

García López, E. (1994): "Un modelo de análisis de evolución arquitectónica e interpretación social. El asentamiento del Bronce Final-Primera Edad del Hierro del Alto de la Cruz (Cortes, Navarra)", Pyrenae, 25, pp. 93-110.

Garcia i Rubert, D.; Gracia, F.; Montero, I.; MoreNo, I. y Rovira, M. C. (2007): "Estudio de composición mediante ED-XRF de materiales metálicos del asentamiento protohistórico de Sant Jaume Mas d'en Serrà (Alcanar, Montsià, Tarragona)". En Molera, J.; Farjas, J.; Roura, P. y Pradell, T. (eds.): Avances en Arqueometría 2005. Actas VI Congreso Ibérico de Arqueometría (Girona, 2005). Girona, pp. 145-152.

García-Arilla, A. (2015): "Dos hachas de talón y anilla halladas en el yacimiento de 'El Morredón' (Fréscano, Zaragoza) y las hachas de talón en el noreste 
peninsular", Cuaderno de Estudios Borjanos, LVIII, pp. 13-34.

García-Arilla, A. y Mesa, M. (2016): “A propósito de un broche o aplique de cinturón hallado en el yacimiento de Burrén-Burrena (Fréscano, Zaragoza)", Cuadernos de Estudios Borjanos, LIx, pp. 29-45.

Gómez Ramos, P. (1993): “Tipología de lingotes de metal y su hallazgo en los depósitos del Bronce Final de la Península Ibérica", Cuadernos Prehistoria y Arqueología de la Univ. Autonoma de Madrid, 20, pp. 73-105.

Maluquer, J.; Gracia, F. y Munilla, G. (1990): "Alto de la Cruz (Cortes, Navarra): campañas, 1986-1988”, Trabajos de Arqueología Navarra, 9, pp. 11-245.

Maya, J. L.; Cuesta, F. y López, J. (eds.) (1998): Genó: un poblado del Bronce Final en el Bajo Segre (Lleida). Barcelona: Public. de la Univ. de Barcelona.

Monteagudo, L. (1977): Die Beile auf der Iberischen Halbinsel, Prähistoriche Bronzefunde, Abteilung Ix, 6. Band. München.

Montero, I. (2010): "Tecnología de la metalurgia de base cobre". En Montero, I. (coord.): Manual de Arqueometalurgia. Cursos de Formación Permanente para Arqueólogos, 1. Madrid: MAR-Colegio de Licenciados de Madrid, pp. 159-188.

Montero-Ruiz, I.; García-Vuelta, O. y Armada, X. L. (2014): "Estudio arqueometalúrgico del depósito de hachas de talón de Distriz (Monforte de Lemos, Lugo)", Sautuola, xIx, pp. 139-156.

Montero, I.; Rafel, N.; Rovira, M. C.; Armada, X. L.; Graells, R.; Hunt, M.; Murillo-Barroso, M.; RenZi, M. y Santos, M. (2012): "El cobre de Linares como elemento vinculado al comercio fenicio en El Calvari de El Molar (Tarragona)", Menga, 3, pp. 167-184.

Montero, I. y Rovira, S. (2010): "Introducción a la Arqueometalurgia”. En Montero, I. (coord.): $M a-$ nual de Arqueometalurgia. Cursos de Formación Permanente para Arqueólogos, 1. Madrid: MAR-Colegio de Licenciados. Madrid, pp. 19-52.

Montero, I.; Santos, M.; Rovira, M. C.; Renzi, M.; Murillo-Barroso, M.; Hunt, M.; Gener, M. y Castanyer, P. (2010-2011): "Lingotes plano-convexos de cobre en la primera mitad del I milenio AC en la Península Ibérica”. En Homenaje a D. Manuel Santonja Alonso. Boletin de la Asociación Española de Amigos de la Arqueología, 46. Madrid, pp. 99-119.

Munilla, G.; Gracia, F. y García López, E. (19941996): "La secuencia cronoestratigráfica del alto de la Cruz (Cortes de Navarra) como base para el estudio de la transición Bronce Final-Hierro en el valle medio del Ebro". En Rovira i Port, J. (coord.): Models d'ocupació, transformació i explotació del territorio entre el 1600 i el 500 ANE a la Catalunya meridional $i$ zones limitrofes de la depressió de l'Ebre (I Taules Rodones d'Arqueologia, Sant Feliu de Codines, 1994). Sant Feliu de Codine: Museu Nacional, pp. 153-173.

Picazo, J. V. y Rodanés, J. M. (coords.) (2009): Los poblados del Bronce Final y Primera Edad del Hierro. Cabezo de la Cruz. La Muela. Zaragoza. Zaragoza: Gob. de Aragón.

Rafel, N.; Montero, I.; Soriano, I.; Hunt, M. A. y Armada, X. L. (2014): "Nuevos datos sobre la minería pre- y protohistórica en Cataluña", Cuadernos de Prehistoria y Arqueología de la Univ. de Granada, 24, pp. 147-166.

RodAnÉs, J. M. a y Picazo, J. V. (2014): "Influencias orientales en el sistema defensivo del Cabezo de la Cruz (La Muela, Zaragoza)", Salduie, 13-14, pp. 213-231.

Rodanés, J. M. a y Picazo, J. V. (2018): “Interaction and Interchange. The genesis of the Late Bronze Age and Early Iron Age in the Middle Ebro Valley". En Cruz, A. y Gibaja, J. F. (eds.): Interchange in Preand Protohistory. Case Studies in Iberia, Romania, Turkey and Israel. BAR Intern. Ser., 2891. Oxford: Archaeopress, pp. 161-176.

Rodríguez de la Esperanza, M. J. (2005): Metalurgia $y$ metalúrgicos en el valle del Ebro. Madrid: RAH-IFC.

Rovira, S. (1993): "La metalurgia de la Edad del Hierro en la península ibérica: una síntesis introductoria”. En Arana, R.; Muños Amilibia, A.; Ramallo, S. y Ros, M. ${ }^{a}$ M. (eds.): Metalurgia en la peninsula ibérica durante el primer milenio a. C. Estado actual de la investigación. Murcia: Univ. de Murcia, pp. 45-70.

Rovira, S. (2004): "Tecnología metalúrgica y cambio cultural en la Prehistoria de la Península Ibérica", Norba. Historia, 17, pp. 9-40.

Rovira, S. (2007): "La producción de bronces en la Prehistoria”. En Molera, J.; Farjas, J.; Roura, P. y Pradell, T. (eds.): Avances en Arqueometría 2005. Actas VI Congreso Ibérico de Arqueometría (Girona, 2005). Girona, pp. 21-35.

Rovira, S. y Renzi, M. (2010): "Las operaciones pirometalúrgicas y sus subproductos". En MonTero, I. (coord.): Manual de Arqueometalurgia. Cursos de Formación Permanente para Arqueólogos, 1. Madrid: MAR-Colegio de Licenciados de Madrid, pp. $87-122$.

Soriano, I. y Hunt, M. A. (2018): "Minería y metalurgia prehistóricas en el Priorat y zonas limítrofes (provincia de Tarragona). Estado de la cuestión”, Revista d'Arqueologia de Ponent, 28, pp. 329-340. 